\title{
DUCTILE REINFORCED CONCRETE FRAMES -
}

\section{SOME COMMENTS ON THE SPECIAL PROVISIONS FOR SEISMIC DESIGN OF ACI 318-71 AND ON CAPACITY DESIGN}

\author{
R. Park" and T. Paulay* *
}

\begin{abstract}
The 1971 building code of the American Concrete Institute contains an appendix with special provisions for the seismic design of reinforced concrete structures. The provisions are based on the code of the Structural Engineers' Association of California and on research evidence and studies of damage to buildings. This paper comments on a number of the provisions for reinforced concrete frames and where necessary indicates where improvements appear to be required. The comments on flexural members and columns cover curvature ductility factors resulting from the flexural steel provisions, the transverse steel required for shear strength, concrete confinement, and restraint against buckling of compression bars, and the affect of cyclic loading. The comments on columns also cover the avoidance of plastic hinges in columns by taking into account the probable distribution of bending moments during dynamic excitation and biaxial bending. The comments on beam-column connections touch on the design of shear reinforcement for joint cores. Some observations on capacity design, and suggestions for capacity design procedures, are also made.
\end{abstract}

\section{INTRODUCTION}

The 1971 ACI code (1) has an appendix containing special provisions for seismic design. According to the Commentary $(2)$ "the provisions of this appendix are intended to apply to reinforced concrete structures located in a seismic zone where major damage to construction has a high possibility of occurrence, and designed with a substantial reduction in total lateral seismic forces due to the use of lateral load-resisting systems consisting of ductile moment resisting space frames with or without special shear walls." The special provisions are not mandatory if load reduction factors for lateral seismic forces are not utilised. The provisions apply to special ductile frames with cast-in-place beam-column connections and to special shear walls used with special ductile frames. The major aim of the philosophy (1) is "to minimize forces by producing a ductile energy-absorbing structural system containing elements the strength of which tends to develop through the formation of plastic hinges rather than through less ductile flexural, shear, or compression failures" The provisions are based on the 1967 and 1968 editions of the SEAOC code( $(3)$ and on research evidence and studies of damage to buildings. The requirements of the appendix "assume that special ductile frames composed of flexural members and columns, with or without special shear walls, will be forced into deformations sufficient to create reversible plastic hinges by the action of the most severe earthquake." The moment capacity of the plastic hinges is calculated using the flexural strength theory from the main body of the code.

This paper mainly discusses the ACI

* Professor of Civil Engineering, University of Canterbury.

** Reader in Civil Engineering, University of Canterbury. provisions for special ductile frames, and makes suggestions for capacity design procedures.

ACI 318-71 PROVISIONS FOR SPECIAL DUCTILE FRAMES

The important requirements stated in the special provisions for seismic design of ACI 318-71(1) are summarized below.

\section{(1) Flexural Members}

An upper limit is placed on the flexural steel ratio $\rho=A_{S} / b d$, where $A_{S}=$ area of tension steel, $b=$ width of the compression face of the member and $d=$ distance from the extreme compression fibre to the centroid of the tension reinforcement. The maximum value of $p$ shall not exceed 0.5 of that value producing a balanced condition, a balanced condition being defined as when the tension steel reaches its yield strength $f_{y}$ just as the concrete in compression reaches an extreme fibre strain of 0.003 . This requirement may be shown (4) to be

$\rho \leqslant 0.5\left[\frac{0.85 f_{c^{\prime} \beta_{1}}^{\prime}}{f_{y}} \frac{0.003 E_{s}}{0.003 E_{s}+f_{y}}+\frac{\rho^{\prime} f_{s}^{\prime}}{f_{y}}\right]$

where $f_{C}^{\prime}=$ compressive strength of concrete, $\beta_{1}=0.85$ for $f_{C}^{\prime} \leqslant 4000 \mathrm{psi}$ $\left(27.6 \mathrm{~N} / \mathrm{mm}^{2}\right)$ or $0.85-5 \mathrm{x} 10^{-5}\left(\mathrm{f}_{\mathrm{c}}^{\prime}-4000\right)$ for $f_{C}^{\prime}>4000$ psi, $E_{S}=$ modulus of elasticity of steel, $\rho^{\prime}=A_{s}^{\prime} / \mathrm{bd}$ where $A_{s}^{\prime}$ = area of compression reinforcement, and $f_{S}^{\prime}=$ stress in compression steel $\leqslant f_{y}$. Provision is also made to ensure that a minimum quantity of top and bottom reinforcement is always present. Both the top and the bottom steel shall consist of not less than two bars and shall have a steel ratio of at least $200 / f_{Y}$, with $f_{Y}$ in psi, throughout the length of the member. Recommendations are also made to 
ensure that sufficient steel is present to allow for unforseen shifts in the points of contraflexure. At connections to columns the positive moment capacity of a beam should be at least $50 \%$ of the negative moment capacity. The beam reinforcement reaching opposite sides of a column should be continuous through the column where possible. At external columns, beam reinforcement should be terminated in the far face of the column with a hook plus any additional extension necessary for anchorage.

Web reinforcement shall be provided for the design shear force. The design shear force shall be calculated on the basis of the design gravity loads on the member and from the moment capacities of plastic hinges at the ends of the member produced by lateral displacement. Fig. 1 illustrates the calculation of the design shear force. The use of the actual ultimate moment capacities of the beams means that the moment induced shears cannot exceed calculated values. Web reinforcement perpendicular to the longitudinal steel shall be provided throughout the length of the member. The minimum size stirrup shall be No. 3 (9.5 mm) and the maximum spacing $d / 4$, where $d=$ effective depth of member. At potential plastic hinge zones (end $4 d$ length of member and other sections where the moment strength may be developed) the stirrup spacing shall not exceed $d / 4$ and the area of shear reinforcement $A_{V}$ within distance $s$ shall not be less than $0.15 A_{S}^{\prime} s / d$ or $0.15 A_{S} s / d$, which ever is larger.

Where bars are required to act as compression reinforcement closed stirrups spaced not further apart than 16 bar diameters or 12 in $(305 \mathrm{~mm})$ should be placed. Such closed stirrups should be placed over the end $2 \mathrm{~d}$ length of the member. Tension steel should not be spliced by lapping in regions of tension or reversing stress unless a specified quantity of closed stirrups are present.

\section{(2) Columns}

The vertical reinforcement ratio is limited to the range 0.01 to 0.06 . Normally, at any beam-column connection the sum of the moment strengths of the column shall be greater than the sum of the moment strengths of the beams along each principal plane at the connection. Exceptions to this requirement are when the sum of the moment strengths of the confined core sections of the column is sufficient to resist the design loads or when the remaining columns and flexural members can resist the applied loads at that level by themselves. The requirement is intended to ensure that plastic hinges form in the beams rather than the columns.

Columns shall be designed as flexural members if the maximum design axial load of the column $\mathrm{Pe}_{e}$ is less than or equal to 0.4 of the balanced failure axial load capacity $\mathrm{Pb}_{\mathrm{b}}$, i.e. $\mathrm{Pe}_{\mathrm{e}} \leqslant 0.4 \mathrm{~Pb}_{\mathrm{b}}$.

If $\mathrm{P}_{e}>0.4 \mathrm{P}_{b}$ the core of the column shall be confined by special transverse reinforcement consisting of hoops or spirals over the end regions of the columns. Each end region is at least equal to the overall column depth, or 18 in $(457 \mathrm{~mm})$, or $1 / 6 \mathrm{th}$ of the clear height of the column. This special transverse steel is to ensure ductility should plastic hinges form at the column ends. Where a spiral is used the volumetric ratio of spiral steel os shall be at least that given by

$\rho_{S}=0.45 \frac{f_{C}^{\prime}}{f_{y}}\left[\frac{A_{g}}{A_{C}}-1\right]$

but not less than $0.12 \mathrm{f}_{\mathrm{c}}^{\prime} / \mathrm{f}_{\mathrm{y}}$, where $\mathrm{A}_{\mathrm{g}}=$ gross area of column section' and $A_{C}=9$ area of core of spirally reinforced column measured to the outside of the spirals. Where rectangular hoop reinforcement is used, the required area of hoop bar shall be calculated from

$A_{s h}=\frac{l_{h} \rho s^{s}}{2}$

where $A_{S h}=$ area of one leg of transverse bar, $I_{h}=$ maximum ansupported length of hoop side measured between perpendicular legs of the hoops or supplementary cross ties, $s_{h}=$ centre to centre spacing of hoops (not to exceed 4 in (102 mm)), and $p_{s}=$ volumetric ratio given by Eq. 2 with area of rectangular core to the outside of hoops substituted for $A_{C}$. Supplementary cross ties, if used, shall be of the same diameter as the hoop bar and shall engage the hoop with a standard hook and shall be secured to a longitudinal bar to prevent displacement during construction. Special transverse confining steel is required for the full height of columns that support discontinuous walls. The shear strength of a column should at least equal the applied shears at the formation of plastic hinges in the frame found from the sum of the moments at the ends of the column divided by the column height. The concrete may be considered to carry shear. Shear reinforcement in columns should be at a spacing not exceeding $d / 2$. Splices in vertical reinforcement shall preferably be made in the midheight regions of columns.

(3) Beam-Column Connections

Special transverse reinforcement through the connection should satisfy Eqs. 2 or 3 . Also the connection should have sufficient shear strength to at least equal the shear forces induced on the joint core by the yield forces of the beam reinforcement and the column shears. A free body of a typical interior connection is shown in Fig. 2. The shear force to be resisted is the total shear force acting on each horizontal section of the joint core. Similar shear strength equations for the concrete shear resisting mechanism and for the transverse reinforcement as used for columns are recommended by the code. Where connections have beam framing in on four sides of the column which cover a substantial proportion of the column face the code allows the required shear reinforcement to be reduced by one half.

DISCUSSION OF ACI 318-71 PROVISIONS FOR SPECIAL DUCTILE FRAMES

(1) Flexural Members

(a) Ductility

The upper limit on tension steel 
content set by Eq. I is an attempt to ensure that plastic hinges in flexural members are capable of ductile behaviour. A measure of the ductility of a section is the curvature ductility factor expressed as the ratio of ultimate curvature to curvature at first yield $(4,5)$. It is of interest to determine the curvature ductility factor ensured by Eq. 1.

The curvature of a section when the tension steel first yields may be found from

$\phi_{y}=\frac{f_{y} / E_{s}}{d(1-k)}$

where $k$ = neutral axis depth factor. In sections with moderate tension steel contents when the tension steel first yields the stress in the extreme fibre of the concrete may be appreciably less than the cylinder strength. In that case the concrete stresses may be assumed to be in the linear elastic range and the neutral axis depth factor $k$ may be calculated using elastic (straight line) theory. The maximum concrete stress when the tension steel first yields should be checked to ensure that linear elastic behaviour of the concrete is a reasonable assumption.

The ultimate curvature of a section may be written as

$\phi_{u}=\frac{\varepsilon_{c}}{a / \beta_{1}}$

where $\varepsilon_{C}=$ extreme fibre concrete compressive strain at ultimate curvature and $a=$ depth of the equivalent concrete compressive stress block. For a given section of the value of a may be found from flexural strength theory using the requirements of strain compatibility and equilibrium. It should be noted that the compression steel is not necessarily yielding at the ultimate curvature. A value for $\varepsilon_{C}$ of 0.004 may be assumed for unconfined concrete, because the value of 0.003 , generally used in strength calculations, is conservature for ultimate curvature calculations.

The curvature ductility factor may be written using the previous expressions as

$\frac{\phi_{u}}{\phi_{y}}=\frac{\varepsilon_{c}}{\varepsilon_{y} / E_{s}} \frac{d(1-k)}{a / \beta_{1}}$

Fig. 3 shows $\phi_{u} / \phi_{y}$ calculated using the above procedure for beams with rectangular cross sections reinforced by different contents of steel with a yield strength of 40,000 psi $\left(276 \mathrm{~N} / \mathrm{mm}^{2}\right)$ The curves are plotted for different concrete strengths and ultimate strains. The curves have been terminated at the lower right hand end when the concrete stress at first yield of the tension steel assuming linear elastic behaviour exceeds the cylinder strength. The curves show the well known feature of increasing ductility with decreasing $\rho$ and increasing $\rho^{\prime}$.

The curvature ductility factor ensured by Eq. I is of interest. Eq. 1 may be rewritten as

$\rho-0.5 \rho^{\prime} f_{S}^{\prime} / f_{Y} \leqslant 0.5 \frac{0.85 f_{c}^{\prime} \beta_{1}}{f_{Y}} \frac{0.003 E_{s}}{0.003 E_{S}+f_{Y}}$
For $f_{\mathrm{y}}=40,000 \mathrm{psi}\left(276 \mathrm{~N} / \mathrm{mm}^{2}\right)$, the limiting value for various concrete strengths is given by:

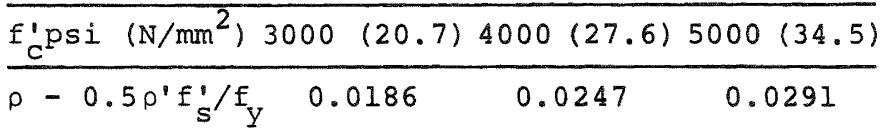

Because the code provisions require at column connections the beam positive moment capacity to be at least $50 \%$ of the beam negative moment capacity, it is evident that at a negative moment plastic hinge in a beam at a column face $\rho^{\prime}$ will be approximately 0.5 or more. With a high compression steel content there is no assurance that the compression steel will be at the yield strength at the ultimate curvature. Reference to Fig. 3 indicates the values of $\phi_{\mathrm{u}} / \phi_{\mathrm{y}}$ which Eq. 1 will ensure are as follows. For sections with $f_{S}^{\prime}=f_{Y}$ and $\rho^{\prime}=0.5 \rho, E q .1$ will ensure $\phi_{\mathrm{u}} / \phi_{\mathrm{y}} \geqslant 5$ when $\varepsilon_{\mathrm{c}}=0.003$ and $\phi_{\mathrm{u}} / \phi_{\mathrm{y}} \geqslant 7$ when $\varepsilon_{c}=0.004$. An extreme fibre concrete strain of 0.004 can be regarded as the maximum strain before concrete crushing occurs. Reference to test results for confined concrete indicates that if reasonable quantities of closed stirrups are present much higher concrete strains can be sustained by the confined core after the concrete has crushed. $(4,5)$. For example, Baker's equation for uitimate concrete strain is

$\varepsilon_{c}=0.0015\left[1+150 \rho_{s}+\left(0.7-10 \rho_{s}\right) \frac{d}{c}\right] \leqslant 0.01$

where $\rho_{S}=$ volume of confining steel to volume of concrete core and $\mathrm{c}=$ neutral axis depth at ultimate moment. No. 3 (9.5 $\mathrm{mm}$ ) closed stirrups at 4 in (102 mm) centres enclosing a 10 in $(25.4 \mathrm{~mm})$ by 20 in $(50.8$ $\mathrm{mm}$ ) beam core results in $\rho_{\mathrm{s}}=0.00825$, which substituted with $c / d=0.25$ into $\mathrm{Eq}$. 7 gives $\varepsilon_{\mathrm{C}}=0.0071$. With an ultimate concrete strain of $0.007, E q .1$ would ensure $\phi_{\mathrm{u}} / \phi_{\mathrm{y}} \geqslant 12$. Hence in general $\phi_{\mathrm{u}} / \phi_{\mathrm{y}} \geqslant 7$ before crushing will be ensured by Eq. 1, and greater values for $\phi_{\mathrm{u}} / \phi_{\mathrm{y}}$ will be reached with crushing of the cover concrete and some reduction in moment capacity at higher strains if the core concrete is confined. At positive moment hinges there will be significant amounts of compression steel available, and a wider flange reducing the $\rho$ value, and hence the available $\phi_{u} / \phi_{y}$ value should be at least that at a negative moment hinge.

Previous considerations $(4,5)$ tend to indicate that the beams of well designed frames should be capable of achieving $\phi_{\mathrm{u}} / \phi_{\mathrm{y}}$ values of at least $4 \mu$, where $\mu$ is displacement ductility factor defined as the ratio of the lateral deflection at the end of the post elastic range to the lateral deflection when yield is first reached. Commonly $\mu$ is assumed to be equal to $l / R$, where $R$ is the reduction factor defined as the ratio of static lateral design load to the elastic response inertia load. A value of $\mu=4$ is often assumed. If $\phi_{u} / \phi_{y}=16$ is sought from beam sections in plastic hinge zones before concrete crushing it is evident that Eq. I may not be stringent enough in some cases and it would be better to use curvature ductility diagrams such as Fig. 3 to check 
that a given section is sufficiently ductile.

Inspection of Fig. 3 indicates that an alternative to $\mathrm{Eq}$. 1 which would result in $\phi_{\mathrm{u}} / \phi_{\mathrm{Y}} \geqslant 15$ at $\varepsilon_{\mathrm{C}}=0.004$ for sections with $f_{y}=40,000 \mathrm{psi}\left(276 \mathrm{~N} / \mathrm{mm}^{2}\right)$ and $\rho^{\prime} \geqslant 0.5 \rho$ is to require

$\rho \leqslant 0.01$ for $f^{\prime}=3000$ psi $\left(20.7 \mathrm{~N} / \mathrm{mm}^{2}\right)$ or $\rho \leqslant 0.0125$ for $\mathrm{F}_{C}^{\prime}=4000 \mathrm{psi}\left(27.6 \mathrm{~N} / \mathrm{mm}^{2}\right)$ or $\rho \leqslant 0.015$ for $\mathrm{f}_{\mathrm{C}}^{\prime}=5000 \mathrm{psi}\left(34.5 \mathrm{~N} / \mathrm{mm}^{2}\right)$

These low tension steel contents may be difficult to achieve when the bending moments to be carried are large. To reduce the tension steel content to the above values may necessitate the use of deeper beams. If this is to be avoided with the curvature ductility factor maintained at 15 before concrete crushing, the compression steel content would need to be increased to greater than $0.5 \rho$. For example, $\rho=0.02$ and $\rho^{\prime}=$ $0.75 \rho$ results in $\phi_{u} / \phi_{y}=13$ for $f_{c}^{\prime}=3000$ psi $\left(20.7 \mathrm{~N} / \mathrm{mm}^{2}\right)$ and $\varepsilon_{C}=0.004$, according to Fig. 3 .

It is to be notted that the above considerations strictly only apply to the first load application into the inelastic range. In a severe earthquake several reversals of loading well into the inelastic range will occur. Moment-curvature relationships for members subjected to large reversed inelastic deformations can be derived theoretically using stress-strain curves for the steel and concrete obtained from cyclic load tests (6). The shape of reversed loading moment-curvature loops can be quite different from curves for a single application of loading. The factors which effect the moment-curvature relationships of sections subjected to large reversed inelastic deformations may be summarized as follows:

(i) The inelastic behaviour of the steel reinforcement. Steel with reversed loading in the yield range shows the Bauschinger effect in which the stress-strain curve becomes nonlinear at a much lower stress than the initial yield strength (see Fig. 4). (ii) The extent of cracking of concrete. The opening and closing of cracks will cause a deterioration of the concrete and hence will result in stiffness degradation. The larger the proportion of load carried by the concrete the larger is this stiffness degradation.

(iii) The effectiveness of bond and anchorage. A gradual deterioration of bond between concrete and steel occurs under high intensity cyclic loading.

(iv) The presence of shear. High shear forces will cause further loss of stiffness due to increased shear deformation in plastic hinge zones under reversed loadings.

The influence of some of these factors on the load carrying capacity and stiffness of a doubly reinforced beam may be seen with reference to Fig. 5. When the beam is loaded downwards well into the post-elastic range of the tension steel, the large cracks shown in Fig. $5 a$ will not close completely on unloading but will remain open as in Fig. $5 \mathrm{~b}$ because of the residual plastic strains in the steel. If the member is then loaded in the opposite direction as in Fig. $5 \mathrm{c}$ the resistance to rotation will be less than that during the first loading because the presence of open cracks in the compression zone means that the whole of the compression is carried by the compression steel. Thus the flexural rigidity of the section is only that of the steel and this is further reduced when the compression steel reaches the stress level at which the Bauschinger effect commences and behaves inelastically. The cracks in the compression zone may eventually close as in Fig. $5 d$, depending on the magnitude of the load and the relative amounts of top and bottom steel. When the cracks close the stiffness of the member increases since some compression is then again transferred by the concrete. If the cracks do not close and the member is unloaded the critical section may be cracked throughout its whole depth. The width of this full depth cracking will depend on the amount of yielding and the effectiveness of the bond. If the member is then loaded down, the member will initially act again as a steel beam, since the concrete is not in contact at the face of the crack.

Fig. 6 shows the effect of the opening and closing of cracks and the Bauschinger effect of the steel on the moment-curvature relationship for a doubly reinforced section. Note that for unsymmetrically reinforced sections the cracks on the side of the member where the steel area is greatest will not close at all during the loading cycles because the other area of steel is too small to cause the large area of steel to yield in compression. The rounding and pinching in of the loop in Fig. 6 means that the often used elastoplastic idealization is no more than a crude assumption. Also the rounding and pinching of the loops means that the area within the loops is smaller than the corresponding area based on the elastoplastic assumption, and thus there will be less energy dissipation per cycle than normally assumed. Generally the flexural strength of a beam is unaffected by the reduced stiffness caused by cyclic loading since the flexural strength is reached at greater deflections. The maximum moment carrying capacity does not reduce with cyclic loading unless crushing of the concrete causes a reduction in the concrete cross section. However, the opening and closing of cracks in zones which alternate between tension and compression may eventually lead to a deterioration in the compressive strength of the concrete because the faces of the crack might not come into even contact, due to slight relative lateral movement or the collection of debris in the crack. This points to the necessity for good concrete confinement even if analysis for monotonic loading indicates that concrete confinement is not required. Closed stirrups at a spacing not greater than 4 in $(102-m)$ should be provided in plastic hinge zones. The maximum spacing allowed, $\mathrm{d} / 4$ for web shear reinforcement, may not provide adequate confinement in large members.

The code provision that longitudinal beam reinforcement should be continuous through interior columns is apparently for anchorage reasons. This provision means that all beam steel should be carried through the joint. However, such a provision may result in undesirable increases 
in moment capacity if all the steel is not required on one side of the joint. To limite the moment capacity where necessary it may be better to bend up some bottom steel, for example, into an interior column at the far face.

\section{(b) Shear Strength}

The ACI provisions recommend the design of shear reinforcement by normal procedures which do not take into account the possible deterioration of the shear carried by the concrete during high intensity reversed loading. Reversal of moment in plastic hinge regions causes a reduction in the shear force carried by the concrete across the compression zone, by aggregate interlock and by dowel action. This is because at some stages full depth open flexural cracks will exist in the member in such regions with moment carried only by a steel couple, and there will be alternating opening and closing of diagonal tension cracks. If full depth cracks exist the shear force will be carried mainly by dowel action of the reinforcement and by greatly diminished aggregate interlock shear. Significant shear transfer by dowel action is associated with large shear displacements which may cause longitudinal splitting of the concrete along the flexural bars and will lead to further loss of bond and consequent stiffness degradation. If the shear force to be transferred across the plastic hinge region is very large, the phenomenon discussed above may lead to a failure by sliding shear along a continuous wide vertical crack across the critical section and additional stirrup reinforcement will do little to alleviate this situation. The role of stirrups is then only to provide support for the flexural reinforcement and so enable it to transfer shear by dowel action. There is evidence that indicates that shear stresses of the order of $10 \sqrt{ } \mathrm{fC}_{\mathrm{C}}^{\prime} \mathrm{psi}\left(0.83 \sqrt{\mathrm{f}} \mathrm{C}_{\mathrm{C}}^{\mathrm{N}} \mathrm{N} \mathrm{mm}^{2}\right)$, allowed by the code, cannot be sustained across full depth flexural cracks when alternating opening occurs due to seismic type loading. It is suggested that the nominal shear stress intensity in plastic hinge zones under such circumstances should be limited to $6 \sqrt{ } f_{C}^{\prime}$ psi $\left(0.5 \sqrt{ } f_{C}^{\prime} \mathrm{N} / \mathrm{mm}^{2}\right)$ or less.

In the plastic hinge zone the contribution of the concrete to shear strength $\mathrm{v}_{C}$, associated with diagonal tension failure mechanisms, also diminishes with reversed cyclic loading, because the width of the diagonal cracks is influenced by the yielding of the flexural steel. Therefore the whole of the shear force should be resisted by stirrups. This amounts to assuming that $\mathrm{v}_{\mathrm{C}}=0$, where $\mathrm{v}_{\mathrm{C}}=$ nominal shear stress carried by the concrete shear resisting mechanisms.

\section{(c) Buckling of Reinforcement}

In plastic hinge regions at large deformations there is a danger of reduction in ductility due to buckling of compression reinforcement. The provisions require closed stirrups spaced not further apart than 16 bar diameters or 12 in $(305 \mathrm{~mm}$ ) in regions where bars act as compression reinforcement. Cyclic (reversed) loading of steel causes a reduction in the tangent modulus of elasticity of the steel at low levels of stress (see Fig. 4) due to the Bauschinger effect and this could lead to buckling of reinforcing bars in compression at lower levels of load than expected. It is recommended that in plastic hinge zones the spacing of closed stirrups surrounding the compression steel should not exceed 6 bar diameter. This closer spacing should be sufficient to restrain buckling under reversed load conditions.

\section{(2) Columns}

\section{(a) Avoidance of Plastic Hinges}

The provisions aim at having plastic hinges form in the beams rather than the columns by requiring that the sum of the moment strengths of the columns exceed the sum of the beam strengths at a connection in each principal plane, except where special provisions are made. The provision allowing stronger beam moment strength if the confined column core sections are capable of resisting the design loads is difficult to understand because it will lead to column hinging in a severe earthquake. This provision should be deleted. However, even having the sum of the moment strengths of the columns greater than the sum of the moment strengths of the beams in each principal plane unfortunately will not prevent column hinging for the two reasons discussed below.

Distribution of Column Moments: Nonlinear dynamic analyses of framed structures responding to earthquakes (see for example, Kelly (7), have indicated that at various times during the earthquake it is possible to have points of contraflexure in columns well away from the midheight of columns. Columns may even be in single curvature throughout a storey at times. One reason for this expected distribution of bending moments is the strong influence of the higher modes of vibration at times. Thus bending moment distributions such as in Fig. 7 are possible. At a typical joint the total beam moment input is resisted by the sum of the column moments and therefore

$\sum M_{b}=M_{b 1}+M_{b 2}=M_{c l}+M_{c 2}$

The greatest column moment is given by

$M_{C l}=\sum M_{b}-M_{c 2}$

Thus if $\left[M_{u b}\right.$ is the total input when the beams are at ultimate moment capacity, and $\mathrm{Mucl}_{\mathrm{ucl}}$ is the ultimate moment capacity of column 1, for a plastic hinge not to form in column 1 requires that

$M_{u c l}>\sum_{u b}-M_{c 2}$

If the column is in double curvature with the point of contraflexure at midheight $\mathrm{M}_{\mathrm{C} 2}=\mathrm{M}_{\mathrm{Cl}}=\mathrm{M}_{\mathrm{UCl}}$ and $\mathrm{Eq}$. 9 requires $\mathrm{M}_{\text {UCl }}>\frac{1}{2} \mathrm{M}_{\mathrm{ub}}$, which is the ACI requirement if the column strengths above and below the joint are equal. If the point of contraflexure moves away from midheight but the column remains in double curvature, the limiting case is when $\mathrm{M}_{\mathrm{C} 2} \rightarrow 0$ and $\mathrm{Eq} .9$ requires that $\mathrm{M}_{\mathrm{ucl}}>\sum \mathrm{M}_{\mathrm{ub}}$. If the columns are in single curvature, Eq. 9 requires 
that $\mathrm{M}_{\mathrm{UCl}}>\sum \mathrm{M}_{\mathrm{Ub}}+\mathrm{M}_{\mathrm{C2}}$. Thus the ACI requirement, that the sum of the column strengths shall exceed the sum of the beam strengths at a joint, will not prevent column hinging in the general case. To make certain that plastic hinges do not form in columns would mean requiring that the flexural strength of each column section should at least equal the sum of the flexural strengths of the beam sections in the plane of bending if the point of contraflexure can be anywhere within the storey height. If the point of contraflexure lies outside the storey height an even greater column capacity would be required. This point is discussed further in the section on capacity design.

Biaxial Load Effects: Although earthquake ground motions occur in random directions it has been the practice in seismic design to consider seismic loading to act only in the direction of the principal axes of the structure and only in one direction at a time. In fact, a general angle of seismic loading can produce a very severe condition in a building structure and it may be extremely difficult to prevent plastic hinges forming in columns in the general case of loading. The effects of biaxial loading, discussed previously by Armstrong (8), Row (9) and others, may be illustrated with reference to the symmetrical building structure with plan as shown in Fig. 8 a subjected to lateral seismic loading in a general direction. Let a floor of the building deflect in the direction of the loading as shown in Fig. 8b. It is evident that the angle $\theta$ need not be very large before yielding will be enforced in the beams in both directions. For example, if a displacement ductility factor $\mu=\Delta_{u} / \Delta_{y}$ of 4 is reached in direction 2 , it only requires $\Delta_{1}=\Delta_{2} / 4$ to cause yielding in direction 1 as well. Thus for a displacement ductility factor of 4 , the loading need only be inclined at an angle $\theta=\tan ^{-1} 0.25=14^{\circ}$ to one principal axis of the building to cause yielding in both directions of a symmetrical building. Thus yielding of beams in both directions may occur simultaneously for a significant part of the loading. Simultaneous loading of the beams in both directions will reduce the flexural strength of the columns because the biaxial bending capacity of columns is less than the uniaxial capacity. Simultaneous loading of beams will also increase the total beam moment input to the columns because of the components of moment strength received from the beams in the two directions. For example, if biaxial bending increases the total beam input moment by $41 \%$ (as it would for beams of equal strength in each direction loaded to the flexural strength simultaneously) and if biaxial bending reduces the column strength by $29 \%$ (possible for high steel ratio, but more likely to be closer to 15\%), the columns would need to be twice as strong as for the uniaxial bending case to avoid column hinging. The situation can be particularly serious at corner columns where, in addition to biaxial bending effects, the earthquake induced axial load input from two beams at right angles can also be additive.

It is apparent that the simple ACI provisions will not prevent plastic hinges forming in columns. In the general case, shifts of points of contraflexure away from mid heights of columns, and loading not applied along a principal axis, will mean that column strengths considerably greater than the ACI requirement would be required. The difficulty of preventing plastic hinges forming in columns is such that some column hinging must be considered to be inevitable in most structures during a major earthquake.

\section{(b) Ductility}

It is evident that some plastic hinging of columns must be considered as likely during a very severe earthquake unless provisions more stringent than those at present recommended by codes are taken. Also the presence of strength from walls considered to be nonstructural, and strength variations of members, could lead to column hinging. Thus the potential plastic hinge zones of all columns should be capable of ductile behaviour.

The code provisions require the end regions of columns to be confined by special transverse steel in the form of spirals or rectangular hoops if the maximum design axial load exceeds 0.4 of the balanced failure load. The quantity of special transverse steel is given by Eqs. 2 or 3 .

Eq. 2 for spiral steel is based on the requirement that the axial load strength of a spiral column after the concrete cover has spalled off should at least equal the axial load strength of the column before spalling (2). Eq. 3 for rectangular hoops was devised to provide the same confinement in a rectangular core as would exist in the core of an equivalent spiral column, assuming that the efficiency of rectangular hoops as confining reinforcement is $50 \%$ of that of spirals (2). That is, it is assumed that for the same degree of confinement, twice the lateral pressure is required from rectangular hoops than from spirals, considering the transverse steel. to be yielding and the lateral pressure to be uniformly distributed. The provisions allow the unsupported length of hoop side to be substituted for $l_{h}$ in $\mathrm{Eq}$. 3. This results in a reduction in the total area of transverse steel through the section. For example, the introduction of two supplementary cross ties equally spaced across the section would double the number of transverse bars; however $l_{h}$ would be reduced by two-thirds and therefore according to Eg. 3 Ash would be reduced by two-thirds, resulting in a $33 \%$ reduction in transverse steel content across the section. According to the commentary $(2)$ this is to give some recognitiion to the more favourable confinement obtained from the reduced unsupported length of hoop side. However, the reduction does not take the scale of the column into account. It is evident that some maximum value for the distance between legs of hoops or supplementary cross ties should be stipulated, for example, 14 in (356 mm) as in the SEAOC code (3), to ensure a reasonable distribution of transverse steel across the section. It is of interest to note that the SEAOC code provisions for transverse steel for confinement using rectangular hoops are less stringent than those of the ACI code in many cases. The SEAOC code requies a constant transverse steel content which amounts to $67 \%$ of the 
ACI value for a single hoop, $89 \%$ of the ACI value for a hoop with a central supplementary cross tie, $100 \%$ of the ACI value for a hoop with two equally spaced supplementary cross ties, $107 \%$ of the ACI value for hoop with three equally spaced supplementary cross ties, etc.

It should be pointed out that Eqs. 2 and 3 , and SEAOC equation, may not necessarily result in adequate curvature ductility. These two equations are based on a philosophy of preserving the ultimate strength of axially loaded columns after spalling of the concrete cover rather than emphasizing the ultimate deformation of eccentrically loaded columns. The ductility of the concrete will be increased by the presence of the confining steel, and hence these equations will result in improved column behaviour. However, because of the very approximate basis on which the equations have been derived, they can only be regarded as a crude approximation for the amount of confining steel actually necessary to achieve the required ultimate curvatures for the usual case of eccentric loading. The equations are also very severe on columns with small cross sections. For example, if $f_{C}^{\prime}=4000 \mathrm{psi}\left(27.6 \mathrm{~N} / \mathrm{mm}^{2}\right), f_{y}=$ $40,000 \mathrm{psi}\left(276 \mathrm{~N} / \mathrm{mm}^{2}\right)$, and the concrete cover to the hoops is $1 \frac{1}{2}$ in $(38 \mathrm{~mm}$ ), the spacing of $\frac{3}{4}$ in (19.1 $\mathrm{mm}$ ) diameter square hoops indicated by Eq. 3 is 3.2 in ( $80 \mathrm{~mm}$ ) for 24 in $(610 \mathrm{~mm})$ square columns ( $\rho_{\mathrm{S}}=$ $0.0138)$ and 3.0 in $(77 \mathrm{~mm})$ for 12 in (305 $\mathrm{mm})$ square columns $\left(\rho_{s}=0.0351\right)$. The smaller section is required to have a much larger confining pressure on the concrete because of the large effect of the $A_{g} / A_{C}$ ratio in the expression for $\rho_{5}$. Hence the equation may be overly conservative for columns with small cross sections. The effect of spalling of the concrete on the content of transverse steel may be over emphasized by these equations.

A more rational approach for the determination of the transverse confining steel required for adequate ductility would be based on moment-curvature relationships. Moment-curvature relationships provide a measure of the plastic rotation capacity of sections. The approach would be based on determining the amount of transverse steel necessary to make the concrete sufficiently ductile for the column to reach the desired ultimate curvature. In deriving moment-curvature characteristics of eccentrically loaded column sections the following factors need to be taken into account: level of axial load, longitudinal steel content, proportion of column section confined, and the material stress-strain curves. The assumptions made and the method of analysis have been outlined previously (10, 11)

As an example of the approach, Fig. 9 shows a reinforced concrete column section with a transverse steel arrangement consisting of three overlapping hoops. The concrete has $\mathrm{f}_{\mathrm{C}}^{\prime}=4000 \mathrm{psi}\left(27.6 \mathrm{~N} / \mathrm{mm}^{2}\right)$. The steel has $\hat{f}_{\mathrm{Y}}=40,000 \mathrm{psi}\left(276 \mathrm{~N} / \mathrm{mm}^{2}\right)$ and $\mathrm{f}_{\text {su }}=66,800 \mathrm{psi}\left(461 \mathrm{~N} / \mathrm{mm}^{2}\right)$, with strain hardening commencing at 16 times the yield strain. Fig. 10 shows momentcurvature curves plotted in dimensionless form for the section with a load level of $\mathrm{P}=0.3 \mathrm{f}_{\mathrm{C}}^{\prime} \mathrm{h}^{2}$, two longitudinal steel contents
$\left(\rho_{t}=A_{s t} / h^{2}\right)$, and a range of $\mathrm{z}$ values correspondening to various transverse steel contents. For the transverse steel arrangement shown in Fig. 9;

$z=5.6$ for $\frac{3}{4}$ in $(19.1 \mathrm{~mm})$ dia. hoops at 2 in (51 mm) centres.

$z=13$ for in (15.9 mm) dia. hoops at 2.8 in $(71 \mathrm{~mm})$ centres.

$\mathrm{Z}=52.7$ for $\frac{1}{2}$ in $(12.7 \mathrm{~mm})$ dia. hoops at 6 in $(152 \mathrm{~mm})$ centres.

The curves of $\mathrm{Fig} .10$ show a sudden reduction in the moment capacity at the assumed onset of crushing of the concrete cover at an extreme fibre strain of 0.004 . with further curvature the contribution of the concrete to the moment carrying capacity comes from such cover concrete which is at a strain of less than 0.004 and the confined core. At curvatures sufficiently high to cause strain hardening of the tension steel a significant increase in moment is apparent. It is to be noted that it has been assumed that the compression steel does not buckle. The curves illustrate that for this column good confinement (low $\mathrm{Z}$ values) is essential if a reasonable moment capacity is to be maintained after crushing of the cover concrete has commenced. If higher load levels than $0.3 f^{\prime} h^{2}$ had been considered it would have been found that the amount of confining steel was even more important. In general, the higher the axial load level the greater the amount of confining steel required to maintain a reasonable moment carrying capacity at high curvatures after crushing commences. The ACI provisions require special transverse steel if the design load of the column exceeds $0.4 \mathrm{P}_{\mathrm{b}}$, where $\mathrm{P}_{\mathrm{b}}$ is the balanced failure load. A load of $0.4 \mathrm{P}_{\mathrm{b}}$ corresponds to a $\mathrm{P} / \mathrm{f}_{\mathrm{c}}^{\prime} \mathrm{h}^{2}$ value for the section studied of approximately 0.20 to 0.23 and thus special transverse steel would be required in the column of the example. The amount of special transverse steel recommended by the code for the arrangement of hoops used in the example is equivalent to $\mathrm{z}=13$. It is evident from Fig. 10 that for this particular column the quantity of transverse steel specified by the code will ensure that the moment capacity after crushing of concrete has commenced is fairly well maintained at higher curvatures.

The above approach depends very much on the ultimate curvature demand for the column and the assumed stress-strain curves for confined concrete and for steel. At present there is a lack of experimental evidence to allow theoretical analyses to be checked. Tests on large size columns are urgently required to enable the moment-curvature relationshipfor various arrangements of transverse steel to be obtained and compared. The full development of the theoretical method awaits such tests.

The ACI provisions require that supplementary crossties, if used, should engage the hoop with a standard hook. Such an arrangement leaves little concrete cover over the end of the hook ( $\frac{1}{2}$ in ( 12.7 $\mathrm{mm}$ ) minimum cover is allowed by the provisions) and may cause construction difficulties. When column bars are at close spacing around the perimeter of the 
section a possible alternative would be to engage only the column bars with cross ties since confinement can come from column bars as well as hoops. Testing of various arrangements of transverse steel involving overlapping hoops and types of supplementary cross ties are badly needed to establish the efficiency of alternative arrangements.

\section{(c) Shear Strength}

The ACI provisions require the transverse reinforcement to be sufficient to ensure that the shear capacity of the member is at least equal to the shear force at the formation of the plastic hinges in the frame. Transverse reinforcement is assumed to be able to play the role of shear reinforcement and confining reinforcement simultaneously. Shear is assumed to be carried by the concrete shear resisting mechanism, as in the normal design procedure, and hence the provisions take no account of the possible deterioration of the shear capacity of the concrete under reversed loading. As with beams, it appears that the contribution of the concrete to the shear strength, $v_{C}$, in the plastic hinge zones should be taken as zero and the shear force carried entirely by the web reinforcement. Between plastic hinges (i.e. away from the ends of columns) shear can be considered to be carried by the concrete. The requirement that the whole of the shear capacity at the plastic hinges be provided by the web reinforcement may be conservative for high axial compressive loads and future experimental evidence may show that some shear can be carried by the concrete if the axial compressive load is high. It may be reasonable to ignore the shear carried by the concrete when $\mathrm{P}_{u}<\mathrm{P}_{b}$ and to let the concrete carry one half of the normal $\mathrm{v}_{\mathrm{C}}$ when $\mathrm{P}_{\mathrm{u}}>\mathrm{P}_{\mathrm{b}}$.

The provisions also make no mention of the high shear forces which may be induced in a column when earthquake loading acts in a general direction on the structure. The moment input into the column is increased in the general case (see the previous discussion), resulting in a greater shear force, and this enhanced shear force is to be resisted by a section loaded in the direction of its diagonal. The shear strength of diagonally loaded rectangular sections has not been properly investigated. Nevertheless the contribution of web reinforcement to the shear strength can be assessed by summing the components of the web bar forces intersected by the diagonal tension crack.

\section{(d) Buckling of Reinforcement}

As for beams, it is recommended that in plastic hinge zones the spacing of transverse steel surrounding the longitidinal bars should not exceed 6 longitidinal bar diameters, or 4 in (102 mm) if buckling under reversed load conditions is to be restrained.

\section{(3) BEAM-COLUMN JOINTS}

\section{(a) Shear Strength}

The ACI provisions indicate that the shear strength of the joint core may be calculated by summing the contributions from the concrete shear resisting mechanism $V_{C}$ and the transverse reinforcement, using the same shear strength equations as for the columns. Tests conducted at the University of Canterbury, for example (12) have indicated that such a procedure is unsatisfactory when cyclic (reversed) high intensity loading is applied to the joint because the concrete in the joint core breaks down. The mechanism of shear resistance of reinforced concrete joint cores is not fully understood at present but it would appear to be erroneous to base a design procedure for joint cores on test results obtained from flexural members. Recent experimental evidence indicates that the critical crack runs from corner to corner of the joint core, and not at $45^{\circ}$ to the axes of the intersecting members, and a better design procedure would appear to be to provide sufficient transverse reinforcement to resist the total shear force across the corner to corner crack. The contribution of the concrete towards the shear resistance should be ignored when the computed axial compression on the column is small, say when the average stress on the gross concrete area is less than $0.2 f_{c}^{\prime}$.

For external columns only those ties which are situated in the outer two thirds of length of the potential diagonal failure crack should be considered effective, as shown in Fig. 11. Therefore for exterior joints

$A_{V}=\frac{1.5 V_{s} s}{d f_{Y}}$

where $A_{V}=$ total area of tie legs in a set of shear reinforcement, $s=$ spacing of tie sets, $d=$ effective depth of the beam, $v_{S}$ $=$ joint shear carried by ties $=V_{j} / \phi$ if concrete contribution to joint shear is ignored where $\phi$ is the capacity reduction factor for shear, 0.85 . This equation is more severe than ACI $318-71$ if $d_{\text {beam }} / 1.5<d_{\text {column }}$.

For the internal columns the major part of the shear force will be introduced into the joint by bond forces along top and bottom reinforcing bars and it is likely that all ties in joint will participate in the shear resistance. Therefore for interior joints

$A_{V}=\frac{v_{s} s}{\left(d-d^{\prime}\right) f_{Y}}$

where $d^{\prime}=$ distance from extreme compression fibre of beam to centroid of compression steel and the other terms are as previously defined. This equation is more severe than ACI $318-71$ if $\left(d-d^{\prime}\right)_{\text {beam }}<d_{\text {column }}$.

Allowance should be made for the possible overstrength of the beam steel when computing the joint shear $\mathrm{V}_{j}$. The calculation of $\mathrm{V}_{j}$ is illustrated in Figs. II and 2 .

In order to protect the core concrete against excessive diagonal compression an upper limit must be set for the joint shear, normally expressed in terms of a nominal 
shearing stress. Further research is required to establish this value, which may bw well in excess of the corresponding value, suggested for beams, i.e. $10 \sqrt{ } f_{C}^{\prime}$ to $11.5 \sqrt{ } f_{C}^{\prime}$ (psi), on account of confinement.

\section{(b) Confinement}

The nominal shearing stresses, and hence the diagonal compression stresses within the joint core may be very large. These compression stresses are responsible for the eventual destruction of the concrete core when high intensity cyclic loading is applied, particularly if the shear reinforcement is permitted to yield. Effective confinement is therefore imperative in any joint. There is insufficient experimental evidence at hand to be able to determine the amount of confining reinforcement required in a joint but it is suggested that not less than that used in columns (Eqs. 2 and 3 ) should be provided irrespective of the intensity of the axial load on the columns.

Shear reinforcement confines only the corner zones of the joint and horizontal tie legs are quite ineffective in providing restraint against the volumetric increase of the core concrete. Hence additional confining bars must be provided at right angles to the shear reinforcement. These bars should not be placed further than 6 in (150 $\mathrm{mm}$ ) apart. Particular attention must be paid to the confinement of the outside face of external joints, opposite the beam, where very high bond forces need to be developed. Here the role of ties and confining steel can be combined.

Only with effective confinement can the shear capacity of a joint be developed.

\section{(c) Anchorage}

Because of the inevitable loss of bond at the inner face of an exterior joint, development length of the beam reinforcement should be computed from the beginning of the $90^{\circ}$ bend, rather than from the face of the column as shown in Fig. 12a. In wide columns any portion of the beam bars within approximately the outer third of the column could (Fig. 12b) be considered for computing development length. For shallow columns the use of stub beams, as shown in Fig. $12 \mathrm{~b}$, will be imperative. A large diameter bearing bar fitted along the $90^{\circ}$ bend of the beam bars should be beneficial in distributing bearing stresses (see Fig. 12a).

In deep columns and whenever straight beam bars are preferred, mechanical anchorages, as shown in Fig. 12c, could be advantageous.

In interior columns, the loss of anchorage of bars passing through the joint core may also have serious consequences. When a frame is subjected to seismic loading. a bar in a member passing through the joint core of an interior column will be in tension on one side of the joint core and in compression on the other side, as is indicated by the bending moment diagram. In the limit, the bar may be stressed to yield in tension on one side of the joint core and to yield in compression on the other side, and for such a bar twice the yield force of the bar has to be developed by bond within the joint core. Such development requires very high bond stresses and under reversed loading deterioration of bond may result in slip of reinforcement through the joint core. If slip occurs the tension in the bar may become anchored in the beam on the other side of the joint core. Thus the "compression steel" in the beam at the column face may actually be in tension. This will reduce the strength, stiffness and ductility of the section: a particularly serious consequence in such a case is the loss of ductility due to the loss of compression steel.

\section{(d) Joints in Space Frames}

1 The most common joint occurs at the interior of a multistorey frame system where four beams, generally at right angles to each other, meet at a continuous column. When a major seismic disturbance imposes alternating yield conditions along one of the major axes of the building, and thereby generates critical shear stresses across the core of the joint, confinement against lateral expansion of the joint will be provided by the beams at right angles to the plane of the earthquake affected frames. Considerable restraint can be offered by the non-yielding flexural steel in these beams which cross the joint transversely. The ACI provisions take this into account by requiring only one half of the shear reinforcement if beams, having a width of not less than half the width of the column and a depth not less than three fourths of the depth of the deepest beam, are provided on all four sides of the column. However further research on joints with beams on four sides may disclose problems not yet visualised; the ACI assumption may not be safe if extensive beam yielding occurs in both principal directions of the frame.

When the axes of the beams and the columns do not coincide, secondary actions, such as torsion, will be generated. The behaviour of the joint becomes more complex and in the absence of experimental studies only crude provisions can be made for these load conditions. In structures affected by seismicity such joints should be avoided. Torsion so introduced caused heavy damage in buildings during the 1968 Tokachioki earthquake.

For convenience, wind or seismic actions are generally considered to be acting independently along one of the two principal axes of a rectangular building frame. However, as discussed earlier, earthquake loading may occur at an angle to both principal axes and produce an overall skew bending effect. This might mobilise the full strength of all beams framing into a column and thus impose extreme conditions upon the joint core due to the diagonal shear loading. The situation can be particularly critical at corner columns where the axial forces induced in the columns by lateral skew loads, are additive. Laboratory testing of joints with general loading cases is urgently required.

Even under unidirectional load application, coincident with one of the principal axes of a multistorey rectilinear rigid jointed space frame, secondary effects in beams at right angles may occur which could 
cause considerable structural damage. Large joint rotations in a plane frame may introduce torsion into beams which enter such joints at right angles to the plane of action, due to the presence of the floor slab, monolithically cast with the beams. The imposed twist may cause excessive diagonal cracking in beams not subjected to flexure and this may affect their performance when lateral load along the other principal direction of the building is to be resisted.

\section{CAPACITY DESIGN FOR SEISMIC LOADING OF FRAMES}

\section{(1) Introduction to Capacity Design}

It is difficult to accurately evaluate the complete behaviour of a reinforced concrete multistorey frame when subjected to very large seismic disturbances. However, it is possible to design the structure so that it will behave in the most desirable manner. In terms of damage, ductility, energy dissipation or failure, this means a desirable sequence in achieving the complex chain of resistance of a frame. It implies a desirable hierarchy in the failure mode of the structure. To establish any sequence in the failure mechanism it is necessary to know the strength of each failure mode. This knowledge must not be based on safe assumptions or dependable capacities but realistically on the most probable strengths of the structural components, which will be subjected to very large deformations during a catastrophic earthquake.

In spite of the probabilistic nature of the design load or displacement pattern to be applied to the structure, in the light of present knowledge, a deterministic allocation of strength and ductility properties holds the best promise for a successful response and the prevention of collapse during a catastrophic earthquake. This philosophy may be incorporated in a rational eapacity design process which may be described as follows: "In the capacity design of earthquake resistant structures, energy dissipating elements of mechanisms are chosen and suitably detailed, while other structural elements are provided with sufficient reserve strength capacity, to ensure that the chosen energy dissipating mechanisms are maintained at near their full strength throughout the deformations that may occur." To illustrate the design approach the derivation of the design shear force for beams and design loads on columns of frames will be briefly discussed.

\section{(2) Capacity Design for Shear in Beams}

If a non-ductile shear failure is to be suppressed it is necessary to ensure that the dependable shear strength of the beam $V_{d}$ is equal to or larger than the shear force associated with the flexural overstrength $\mathrm{M}_{\mathrm{O}}$ of the beam, which cannot be exceeded during the seismic excitation. In addition to earthquake moment induced shear, provision needs to be made for shear forces resulting from gravity load and vertical accelerations. Hence with reference to Fig. I at the left hand support $A$

$v_{d A} \geqslant \frac{M_{O A}+M_{O B}}{I_{n}}+\lambda_{a} \frac{{ }^{w} I_{n}}{2}$

$$
\text { where } \begin{aligned}
\mathrm{V}_{\mathrm{dA}}= & \text { the dependable shear strength } \\
& \text { of the beam at } \mathrm{A}
\end{aligned}
$$

For routine design it is more convenient to express this relationship in terms of ideal strengths and the appropriate strength factors. Accordingly, Eq. 11 becomes

$v_{i A}=\frac{1}{\phi}\left[\phi_{0} \frac{M_{i A}+M_{i B}}{l_{n}}+\lambda_{a} \frac{w_{n}}{2}\right]$

where $\mathrm{V}_{\text {iA }}$

$=$ the ideal shear strength of the beam at $A$, to be supplied entirely by web reinforcement.

$M_{i A}, M_{i B}=$ the ideal flexural strength of the support sections, i.e. $M_{i A}=A_{S} f_{y} j d$ at support

= the capacity reduction factor for shear, i.e. 0.85

$\phi_{0}$

$=$ the flexural overstrength factor, for example 1.3, taking into account additional strength due to steel yield strength greater than specified, steel strain hardening, effect of steel in slabs, etc.

$\lambda_{a}=$ the allowance for vertical acceleration due to seismic motions, for example 1.25 for $0.25 \mathrm{~g}$.

With above chosen values for $\phi_{,} \phi_{0}$ and $\lambda_{a}$ ' Eq. 12 becomes

$v_{i A}=1.53 \frac{M_{i A}+M_{i B}}{I_{n}}+1.47 \frac{{ }^{w} I_{n}}{2}$

It is evident that the degree of protection against a possible shear failure in seismic design needs to be considerably greater than for gravity or wind load design.

\section{(3) Capacity Design of Columns}

The estimation of column moments and concurrent axial loads in earthquake resistant frames is much more difficult. Before outlining the capacity design procedure relevant to columns it is necessary to restate the design criteria which are intended to be met.

The intention is to avoid plastic hinges forming in columns if possible. One reason for this is that a very large column curvature ductility demand is associated with sidesway collapse mechanisms with plastic hinges only in columns (5). There are also a number of other important reasons why column hinging should be avoided or at least delayed. A column failure has much more serious consequences than a beam failure. Column 
yielding in all columns of a storey will lead to permanent misalignment of the building. Compression load, most commonly present in columns, reduces the available curvature ductility. Column hinging, associated with large interstorey sway, introduces problems of instability, which in turn may jeopardise the gravity load carrying capacity of the structure.

The question that arises is how can a reasonable degree of protection be provided by the designer if the precept is accepted that during a large random dynamic excitation column hinging is to be prevented or delayed, except at a few unavoidable localities.

In accordance with the capacity design philosophy it would be necessary to ensure that the dependable flexural capacity of a critical column section, adjacent to a column-beam joint, it at least equal to the worst probable flexural demand which may occur concurrently with a probable axial load. It is thus necessary to estimate the two actions, moment and axial force, separately. It should be noted that the relationship between moment input and flexural strength in columns need not be as stringent as was the case for shear in beams, because the column sections will have been designed for ductility.

\section{(a) Flexural Demand for Column Sections}

Because of the disproportionate distribution of moments around column-beam joints during the higher modes of response of a multistorey frame, bending moments at the critical sections considerably larger than those derived from static analysis could result. This was pointed out previously with reference to Fig. 7. To minimise the likelihood of column yielding, it will be necessary that the dependable column strength at a critical section, for example above the floor level shown in Fig. 7, be made larger than the probable moment input from the adjoining beams, i.e.

$\mathrm{M}_{\mathrm{dcl}} \geqslant \lambda_{\mathrm{cl}}{\sum \mathrm{M}_{\mathrm{pb}}}$

where $\mathrm{M}_{\mathrm{dcl}}$ = the dependable flexural capacity of the column section in the presence of the appropriate axial load

$\sum \mathrm{M}_{\mathrm{pb}}=$ the sum of the probable beam flexural capacities when plastic hinges form in the beams

$\lambda_{\mathrm{Cl}}=$ a moment distribution factor which depends upon the inelastic dynamic response of the frame when it is subjected to earhtquake ground motions. Case studies (7) have indicated that for regular frames the value for this factor could be between 0.8 to 1.3 , the higher value being observed for a rather flexible frame and the smaller value being representative of a relatively rigid frame which would predominantly respond in its first mode of vibration.

Again Eq. 14 is more conveniently expressed in terms of ideal strengths.

$$
\begin{aligned}
& M_{i c l} \geqslant \frac{c l}{\phi_{C}} \sum \phi_{p b} M_{i b} \\
& \text { where } M_{i c l}= \text { the ideal flexural strength } \\
& \text { of the column section in the } \\
& \text { presence of the design axial } \\
& \text { load } \\
&= \text { the ideal flexural strength } \\
& \text { of the beams } \\
& M_{i b} \text { the probable strength factor } \\
& \text { for the beams taking into } \\
& \text { account actual material } \\
& \text { strengths } \\
& \phi_{\mathrm{pb}} \text { the capacity reduction factor } \\
& \text { for columns }
\end{aligned}
$$

To illustrate the implications of this relationshio, Eq. 15 will be compared with current requirements of the ACI and SEAOC codes, using typical values for the various factors.

According to these two codes it is found that with $\phi_{c}=0.7$ and $\phi_{b}=0.9$

$M_{i c l} \geqslant \frac{0.5}{\phi_{C}} \sum \phi_{b} M_{i b}=0.64 \Sigma M_{i b}$

The SEAOC code stipulates that the beam overstrengths, with $\mathrm{M}_{\mathrm{Ob}}=1.25 \mathrm{M}_{\text {ib }}$, must be considered when determining the shear forces acting on beams, but surprisingly the code does not require this for column bending moment design.

The 0.5 factor in Eq. 16 results from the assumption that the total beam moment input, $\Sigma M_{i b}$, is distributed in equal proportions between the column sections above and below the floor in question.

For the extreme case of disproportionate distribution of column moments, a column capacity reduction factor of $\phi_{c}=0.9 \mathrm{may}$ be considered adequate. Hence by assuming that $\phi_{\mathrm{pb}}=1.1, \mathrm{Eq} .15$ becomes

$$
\begin{aligned}
& M_{i c l} \geqslant 0.98 \sum M_{i b} \text { when } \lambda_{c l}=0.8 \\
& M_{i c l} \geqslant 1.58 \sum M_{i b} \text { when } \lambda_{c l}=1.3
\end{aligned}
$$

In this case no allowance has been made for the possible development of beam overstrength. It is seen that in comparison with the ACI and SEAOC code requirement, the proposed capacity design procedure gives a considerably greater protection against column yielding, the required ideal column strength of Eqs. $17 \mathrm{a}$ and $17 \mathrm{~b}$ being 1.53 and 2.47 times that of the code Eq. 16. In fact it could be inferred from the commentary to the SEAOC code that $\phi_{\mathrm{b}}=\phi_{\mathrm{c}}=1$ may be assumed in Eq. 16 making the required ideal column strength according to that code even smaller.

\section{(b) Axial Load Determination for Columns}

In seismic design it is important to determine accurately the probable earthquake induced axial loads on the columns. These loads are particularly critical in the case of exterior columns. When frames are designed for equivalent static lateral 
loads the corresponding axial loads are readily derived. However these forces are representative of only the first mode response of the structure and they do not reflect the true column loads which can develop in a frame. An approach to determine column loads used in New Zealand assumes, in accordance with capacity design philosophy, that all beams framing into a column develop their flexural over-strengths simultaneously over the full height of the structure. This implies that the column load input at each floor is given by summing the input shear forces from the beams, using shear force equations similar to the right hand side of Eq. 11 with the first term taken as positive or negative depending on the side of the column. The column loads so obtained are then converted into dependable strengths with the introduction of the column capacity reduction factor, $\phi_{C}=0.7$. This procedure appears to be unnecessarily severe, particularly for tall frames. During the inelastic dynamic response of a frame, beam plastic hinges form in groups, typically over 2 to 5 floors at a time, and travel up the full height of the frame (7). Therefore it would be more rational to make some allowance for the fact that not all possible beam plastic hinges are present simultaneously when calculating the earthquake induced column loads.

Such an approach is illustrated for a 20 storey example structure in Fig. 13. For the purpose of deriving the critical lateral load induced column loads for the 6 th storey columns, it may be assumed that the overstrengths, $M$, of all the beams at 6 floors immediately above the 6 th storey are developed. Typically these may be $125 \%$ of the ideal bea, strength, $M_{i b}$, so that $M_{o b}$ $=1.25 \mathrm{M}$ ib. It is unlikely that plastic hinges have formed in the beams of the next 6 floors above, but it may be assumed that say $85 \%$ of the ideal strength of each of the beams at these floors will be developed. For the next 6 floors above, a further reduction to say $75 \%$ of the ideal beam strengths may be assumed, as illustrated in $\mathrm{Fig} .13$.

The column loads so derived would then have to be combined with the appropriate factored gravity loads and vertical acceleration components to give upper bound and lower bound values for the column loads. As these axial loads are based on extreme and transient capacity conditions of behaviour there does not appear to be a need for the introduction of a further capacity reduction

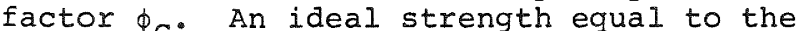
axial load so derived may be sufficient. some reserve strength will be available in any case because the probable strength of the column section will be in excess of the ideal strength, particularly when, as a result of large axial compression, the contribution of the concrete compression strength becomes significant. It is to be remembered that the probable strength of the concrete in place is likely to be well in excess of the ideal strength $f_{C}^{\prime}$.

\section{(c) The Shear Force on Columns}

From the foregoing it is evident that a somewhat larger degree of protection against shear failure in columns must be provided because of its brittle nature. To be con- sistent with the capacity design philosophy one would tend to consider the simultaneous development of plastic hinges at the top and bottom of a column. However, these sections have already been designed separately for the maximum likely moment inputs. As Fig. 14 shows, column bending moments corresponding with two plastic hinges could not occur. Fig. 14 a shows the moment pattern for the case when the column sections could develop $98 \%$ of the total beam moment input at the top and at the bottom of the storey, and Fig. 14b shows the same for $158 \%$ beam moment input, in accordance with Eqs. $17 \mathrm{a}$ and $17 \mathrm{~b}$. The broken line indicates the moment pattern that would result from the current ACI and SEAOC code requirements.

It would be unreasonable to determine the design column shear force from the full $M_{\text {ic }}$ moment at each of the columns since noramily the moment at one end will be considerably less than $M_{i c}$. It is suggested that a reasonable moment pattern from which the maximum likely column shear forces could be derived is shown in Fig. 14C, so that

$v_{i c} \geqslant \frac{1.5 M_{i c}}{\phi I_{u}}$

$$
\begin{aligned}
\text { where } \mathrm{V}_{\text {ic }}= & \text { the ideal shear strengths of } \\
& \text { the column } \\
\mathrm{M}_{i c}= & \text { the ideal flexural strength of } \\
& \text { the column section in the } \\
& \text { presence of that axial load which } \\
& \text { results in a maximum column } \\
& \text { flexural strength } \\
l_{u}= & \text { the clear height of the column } \\
\phi= & \text { the capacity reduction factor } \\
& \text { for shear, } i . e .0 .85 .
\end{aligned}
$$

\section{CONCLUSIONS}

Provisions for Special Ductile Frames

\section{Flexural Members}

The upper limit placed on the tension steel content, Eq. I, will ensure a curvature ductility factor $\phi_{\mathrm{u}} / \phi_{\mathrm{y}} \geqslant 7$ when the extreme fibre compressive strain is 0.004 Hence higher curvature ductility factors will be accompanied by crushing of concrete. A simpler relationship giving $\phi_{\mathrm{u}} / \phi_{\mathrm{y}} \geqslant 15$ at $\varepsilon_{c}=0.004$ for section with $\underline{E}_{y}=40,000$ psi $\left(276 \mathrm{~N} / \mathrm{mm}^{2}\right), \rho^{\prime} \geqslant 0.5 p$ and $3000 \mathrm{psi} \leqslant$ $f_{C}^{\prime} \leqslant 5000$ psi is

$\rho \leqslant 0.01+0.0025\left[\frac{f_{c}^{\prime}}{1000}-1\right]$
with $f_{c}^{\prime}$ in psi $\left(1\right.$ psi $\left.=0.00689 \mathrm{~N} / \mathrm{mm}^{2}\right)$.

In plastic hinge zones closed stirrups at spacing not greater than 4 in (102 mm) or $d / 4$ should be provided to carry the total shear force (the shear carried by the concrete is ignored), and compression steel should be restrained by transverse steel at a spacing not exceeding 6 longitudinal bar diameters. The nominal shear stress at plastic hinges subjected to alternating yielding should be limited to $6 \sqrt{ } f_{C}^{\prime}$ psi $\left(0.5 \sqrt{ } f_{C} \mathrm{~N} / \mathrm{mm}^{2}\right)$. 


\section{Columns}

Plastic hinges in columns are difficult to prevent because shifts of points of contraflexure away from midheight of columns at some time during the earthquake, and seismic loading acting simultaneously along both principal axes of the building, increase the moment input into the columns. Thus detailing of columns for ductility is an important consideration. The present code provisions for special transverse steel are crude approximations and tests on large scale columns to check ductility available from various arrangements of transverse steel are required.

As with beams, in potential plastic hinge zones the total shear force should be carried by the shear reinforcement, unless the axial load level is high, and the compression steel should be supported laterally by transverse steel at spacing not exceeding 6 longitudinal bar diameters or 4 in $(102 \mathrm{~mm})$.

\section{Beam-Column Joints}

The total shear force should be carried across the corner to corner crack. The shear carried by the concrete is ignored unless the axial column load is high. Ties near the extremities of the joint core should be ignored (see Eq. 10). Concrete in the joint core should be adequately confined and attention given to anchorage.

\section{Capacity Design}

A rational capacity design procedure will give a large degree of protection against brittle failures and column yielding. Further research work is required to establish reliable numerical values for the various strength parameters, and the likely range of column moment distributions. To prevent column yielding when seismic loading acts in the direction of both principal axes of the building simultaneously requires columns of large strength.

\section{ACKNOWLEDGEMENTS}

The authors gratefull acknowledge the encouragement and constructive comment received from many professional engineering colleagues in New Zealand and overseas, and also the work conducted by research students and technicians in the Department of Civil Engineering of the University of Canterbury through the years.

\section{REFERENCES}

1. ACI Committee 318, "Building Code Requirements for Reinforced Concrete, (ACI 318-71)", American Concrete Institute, Detroit, 1971, 78pp.

2. ACI Committee 318, "Commentary on Building Code Requirements for Reinforced Concrete (ACI 318-71)", American Concrete Institute, Detroit, 1971, $96 \mathrm{pp}$.

3. SEAOC, "Recommended Lateral Force Requirements and Commentary", Seismology Committee, Structural Engineers' Association of California, San Francisco, $1973,146 \mathrm{pp}$.

4. Park, R. and Paulay, T., "Ultimate Stength Design of Reinforced Concrete Structures", Seminar Notes University of Canterbury.

5. Park, R., "Ductility of Reinforced Concrete Frames Under Seismic Loading", New Zealand Engineering, Vol. 23, November 1968, pp.427-435.

6. Park, R., Kent, D. C. and Sampson, R.A., "Reinforced Concrete Members with Cyclic Loading", Journal of Structural Division, American Society of Civil Engineers, Vol. 98, ST7, July 1972, pp.1341-1360.

7. Kelly, T. E., "Some Seismic Design Aspects of Multistorey Concrete Frames", Master of Engineering Report, University of Canterbury, 1974, 163pp.

8. Armstrong, I. C. "Capacity Design of Reinforced Concrete Frames for Ductile Earthquake Performance", Bulletin of New Zealand Society for Earthquake Engineering, Vol. 5, No. 4, December, 1972, pp.133-142.

9. Row, D. G.," "The Effects of Skew Response on Reinforced Concrete Frames", Master of Engineering Report, University of Canterbury, 1973, 101pp.

10. Park, R. and Sampson, R. A., "Ductility of Reinforced Concrete Column Sections in Seismic Design", Journal of American Concrete Institute, Proc. Vol. 69, No. 9, September 1972, pp.543-551.

11. Park, R. and Norton, J. A., "Effects of Confining Reinforcement on Flexural Ductility of Rectangular Reinforced Concrete Column Sections with High Strength Steel", Symposium on Safety and Design of Reinforced Concrete Compression Members, Reports of Working Commissions, Vol. 16, International Association for Bridge and Structural Engineering, Quebec, 1974, pp. 267-275.

12. Park, R. and Paulay, T., "Behaviour of Reinforced Concrete External BeamColumn Joints Under Cyclic Loading", Proceedings of the 5 th World Conference on Earthquake Engineering, Rome, June 1973 

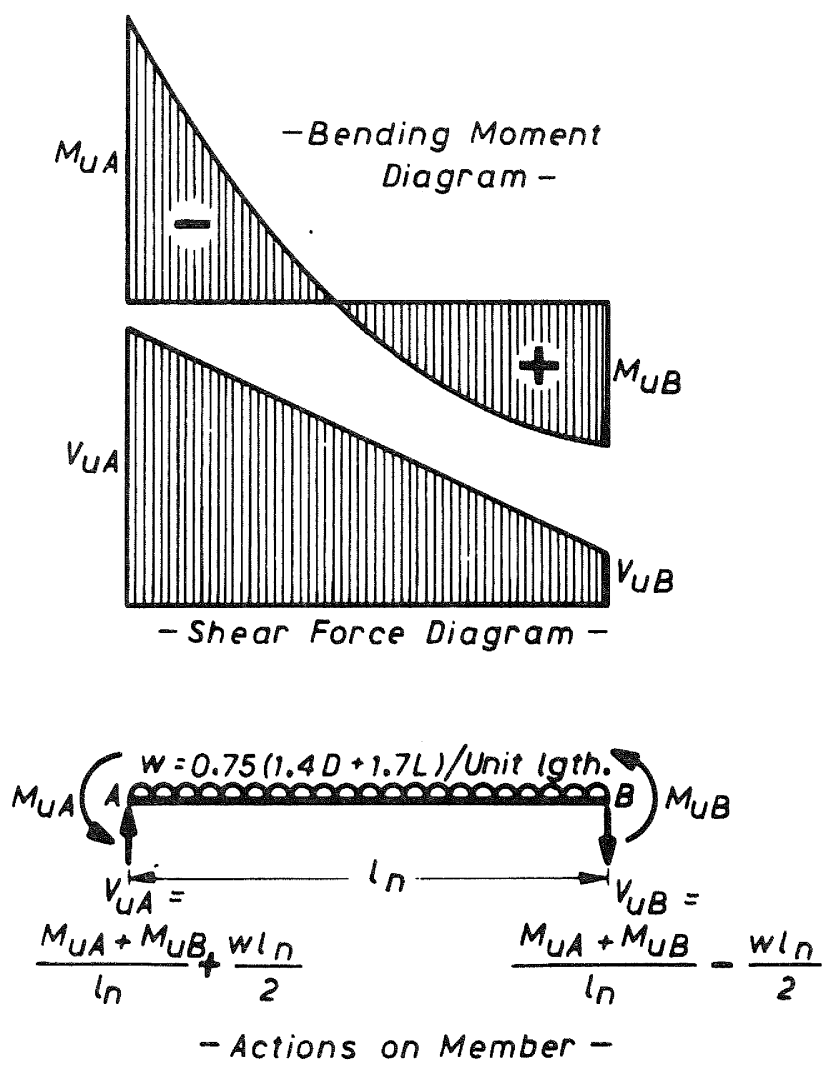

Fig. I Calculation of beam shear force with seismic loading.

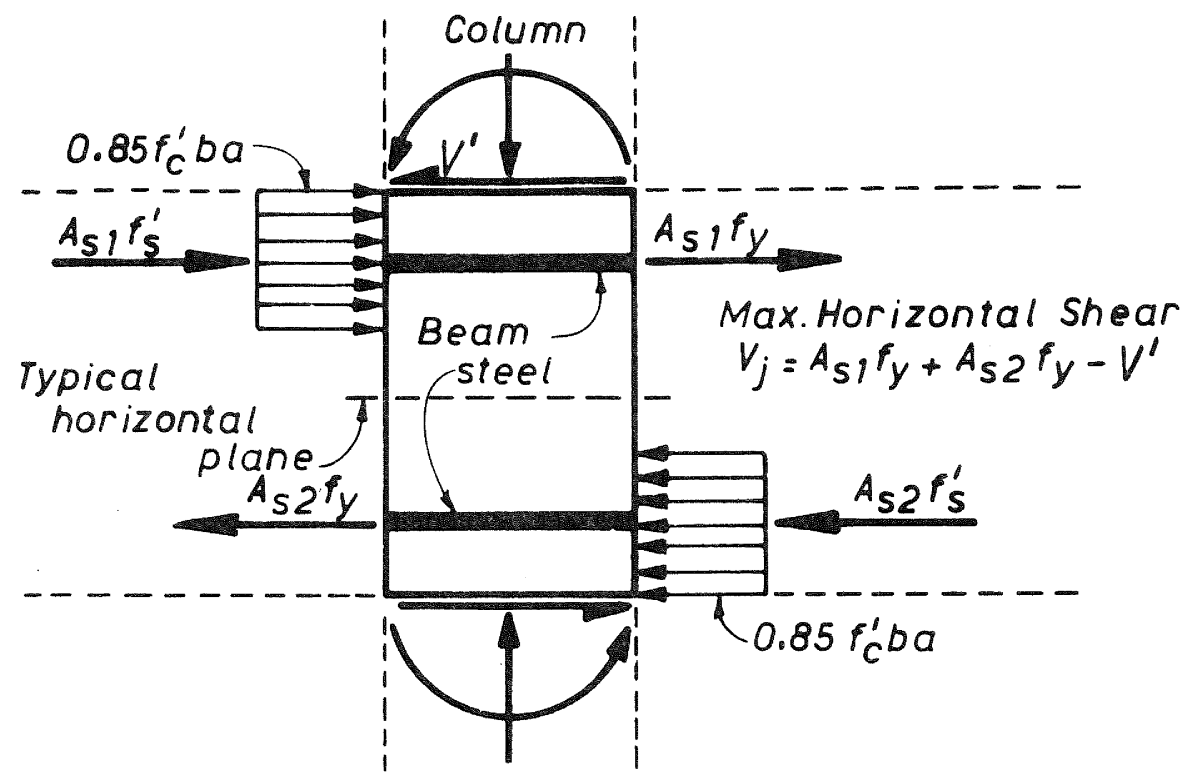

Fig. 2 Horizontal shear forces acting on an interior beamcolumn joint core during seismic loading. 

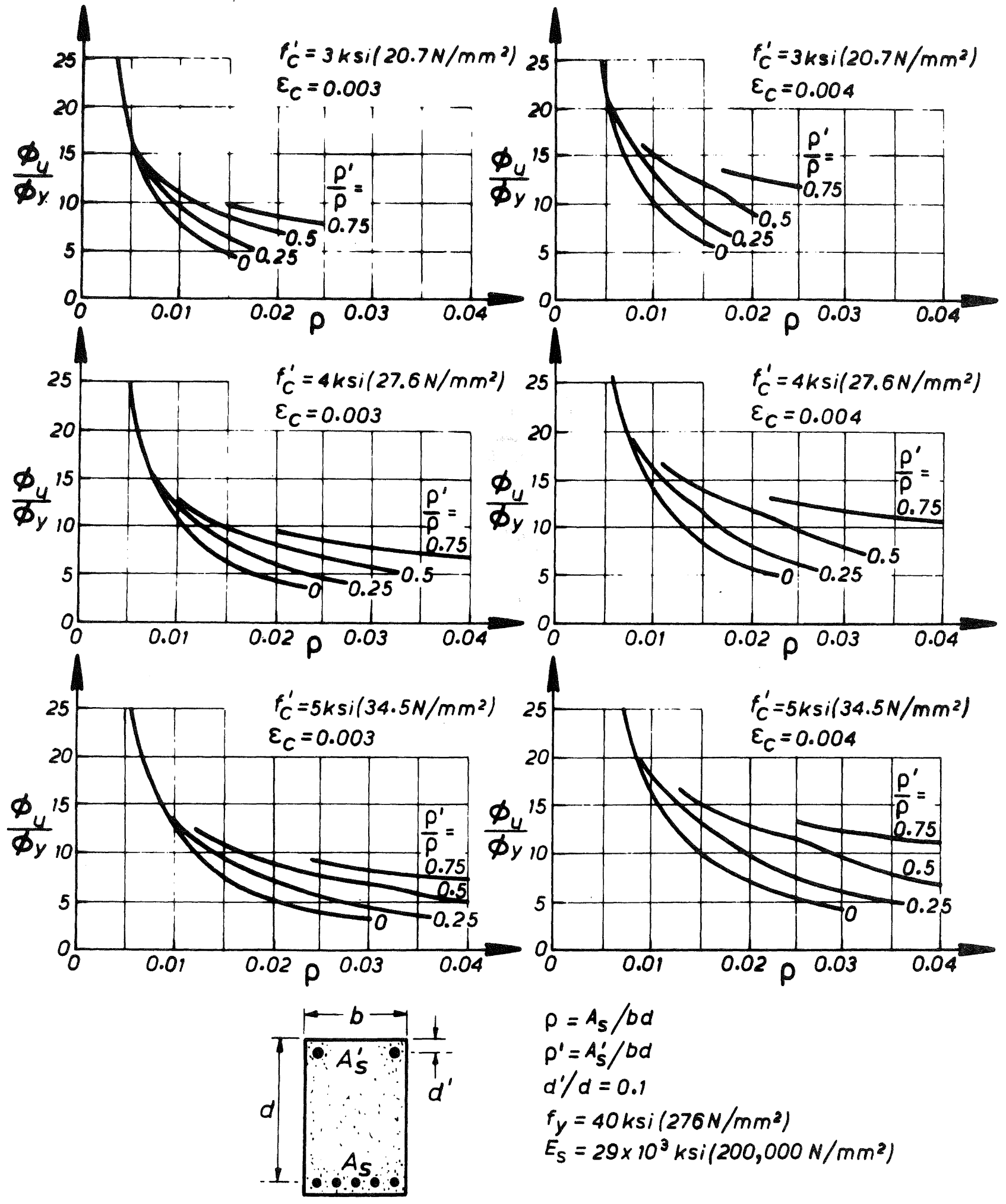

Fig. 3 Variation of curvature ductility factor $\phi_{\mathrm{u}} / \phi_{\mathrm{Y}}$ for beams with unconfined concrete and $f_{y}=40 \mathrm{ksi}\left(276 \mathrm{~N} / \mathrm{mm}^{2}\right)$. 


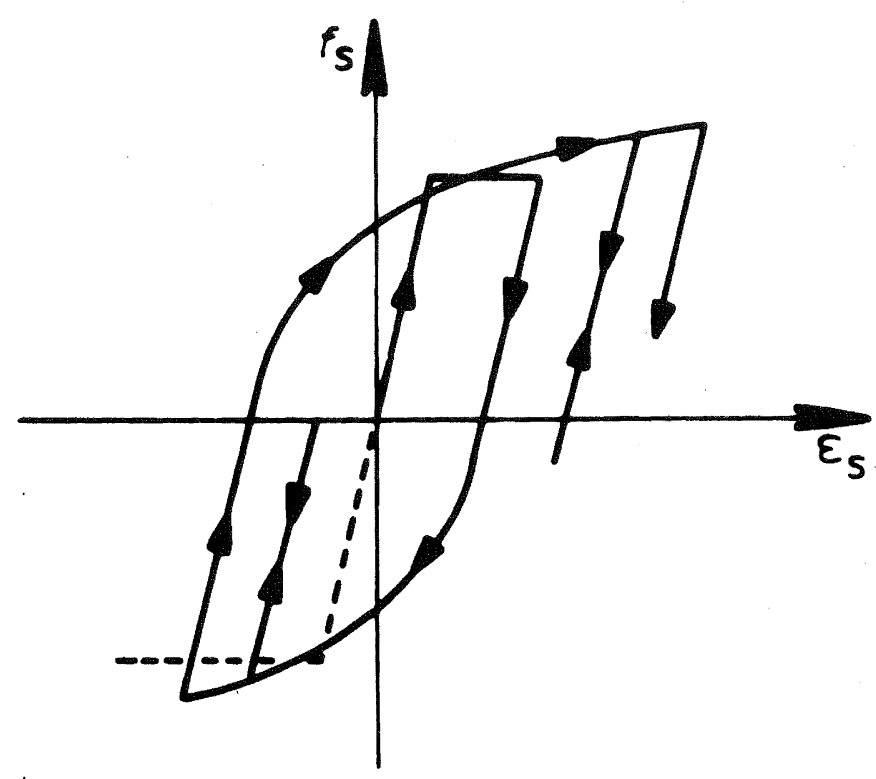

Fig. 4 Stress-strain curve for steel with cyclic loading illustrating the Bauschinger effect.

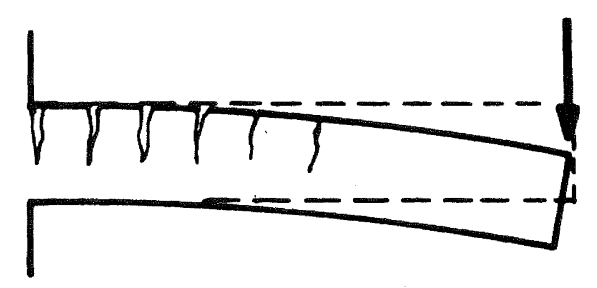

(a) At end of first loading

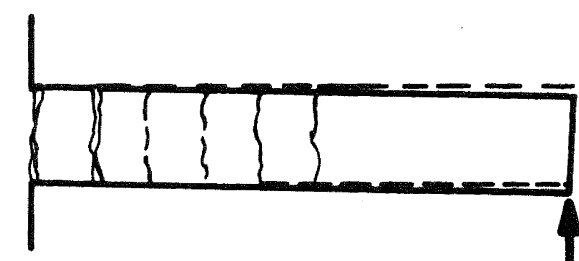

(c) At start of reversed loading

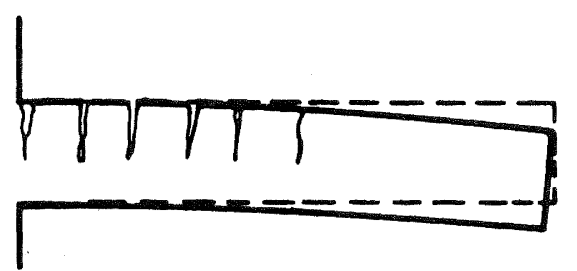

(b) After unloading

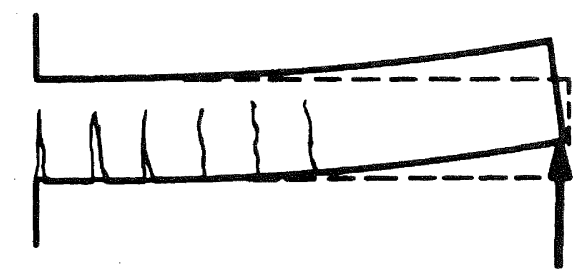

(d) At end of reversed loading

Fig. 5 Effect of reversed loading on reinforced concrete cantilever beam. 


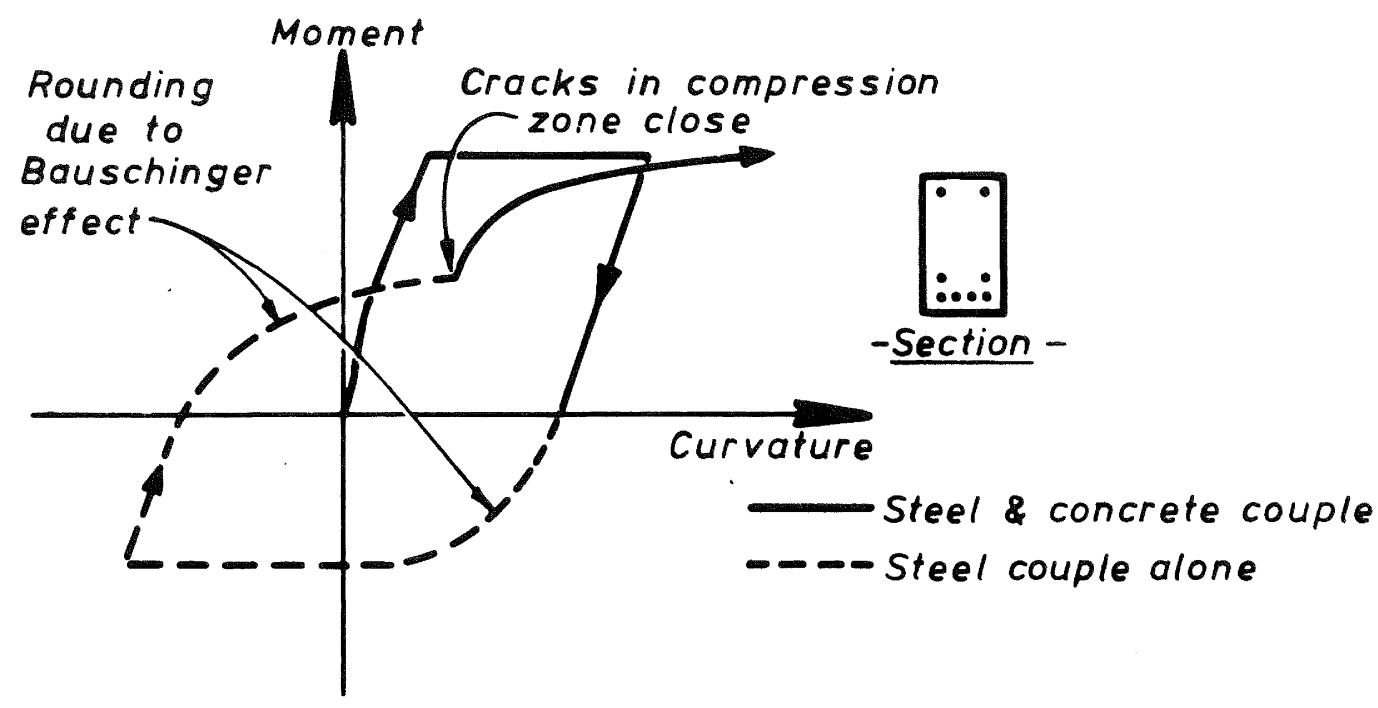

Fig. 6 Moment-curvature relationship for doubly reinforced section with reversed flexure.
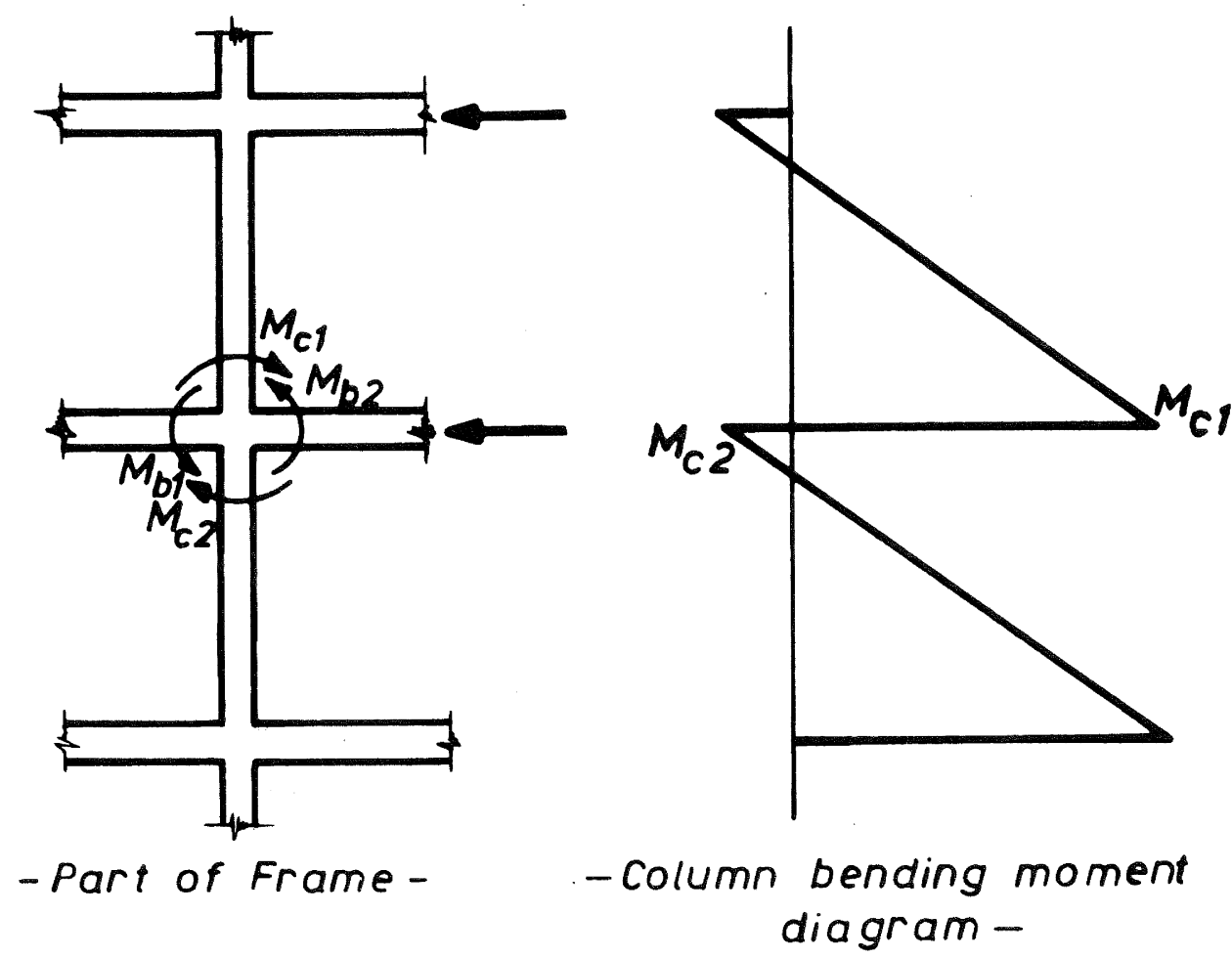

Fig. 7 Moments at beam-column joint. 


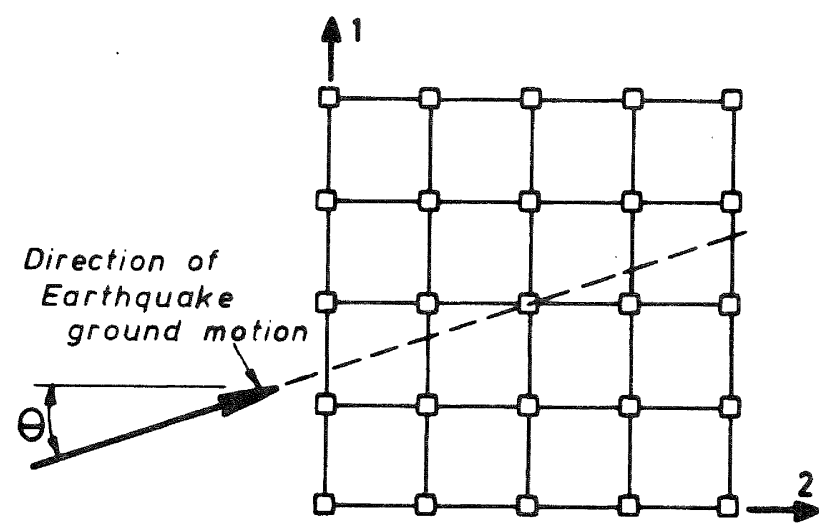

(a) Plan of building

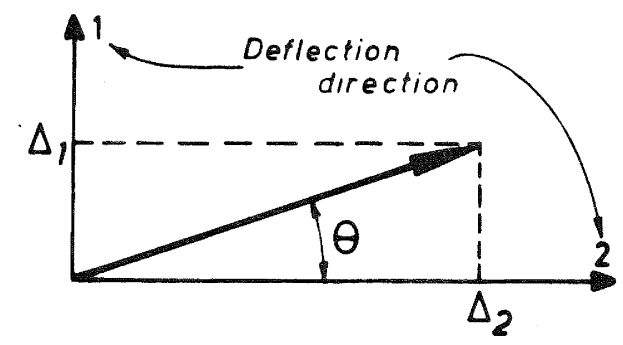

(b) Deflection of a floor

Fig. 8 General direction of earthquake loading on building.

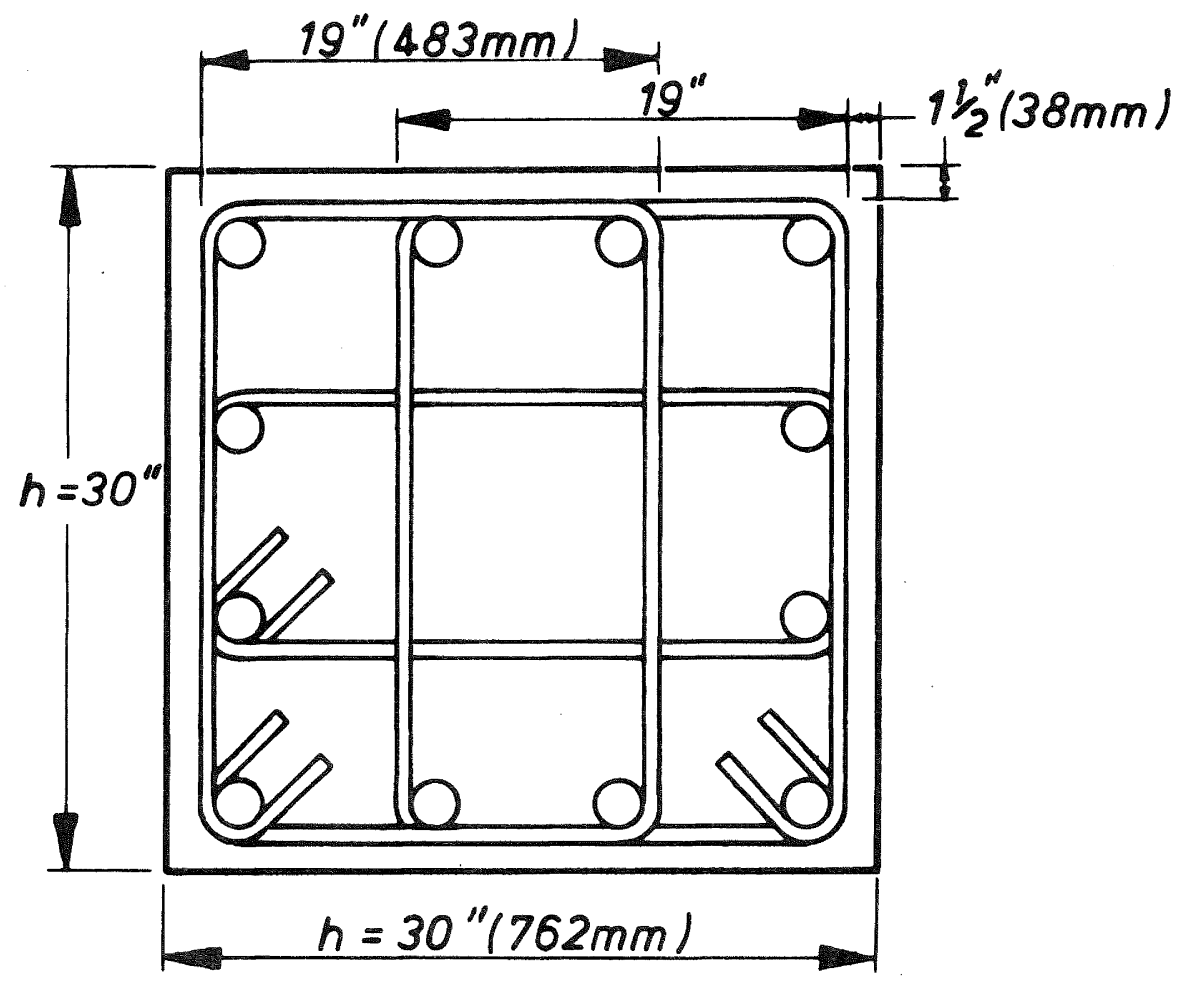

Fig. 9 Possible transverse steel arrangement. 


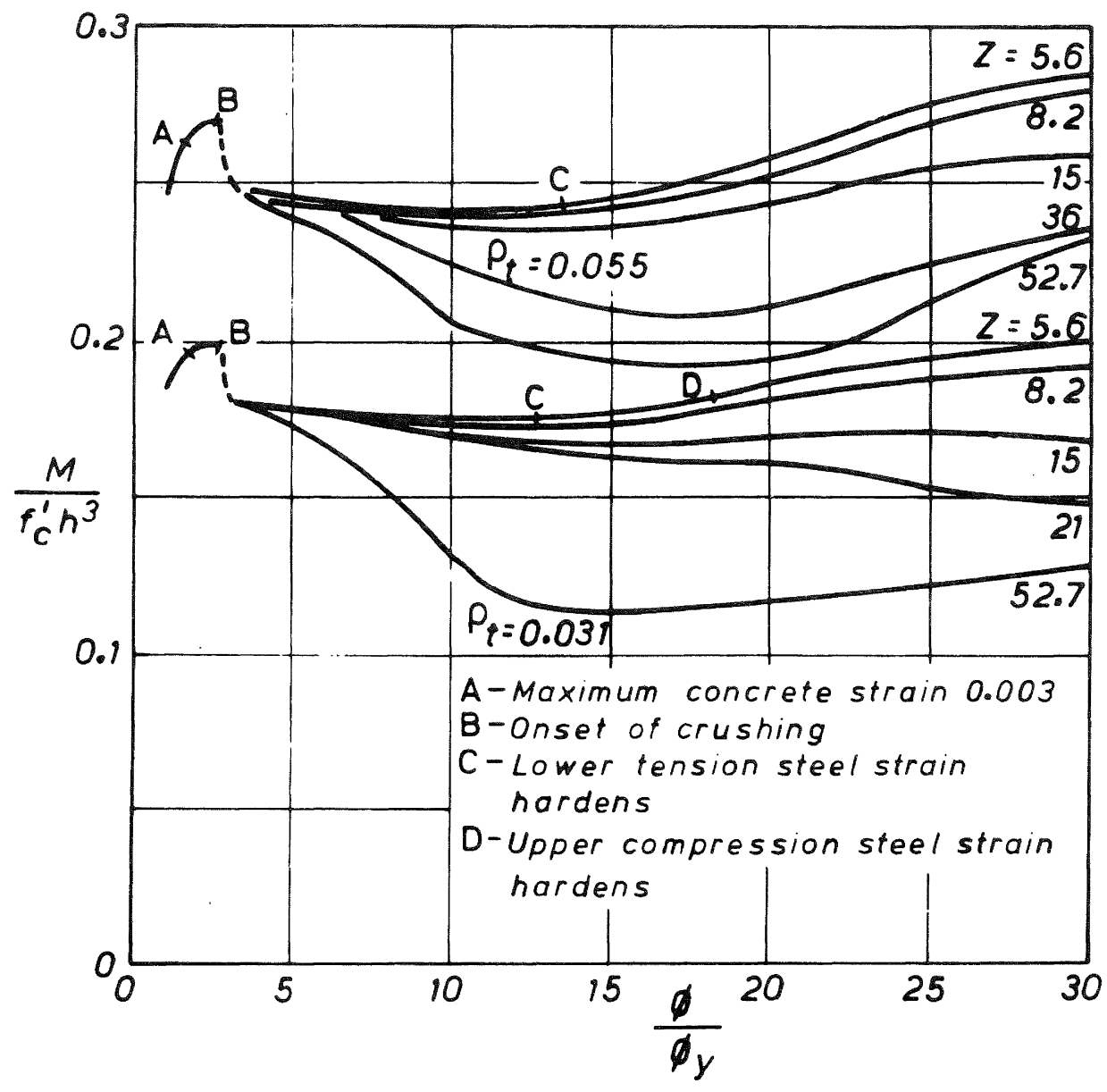

Fig. 10 Moment-curvature ductility curves for column section with $P=0.3 f_{C}^{\prime} h^{2}$.

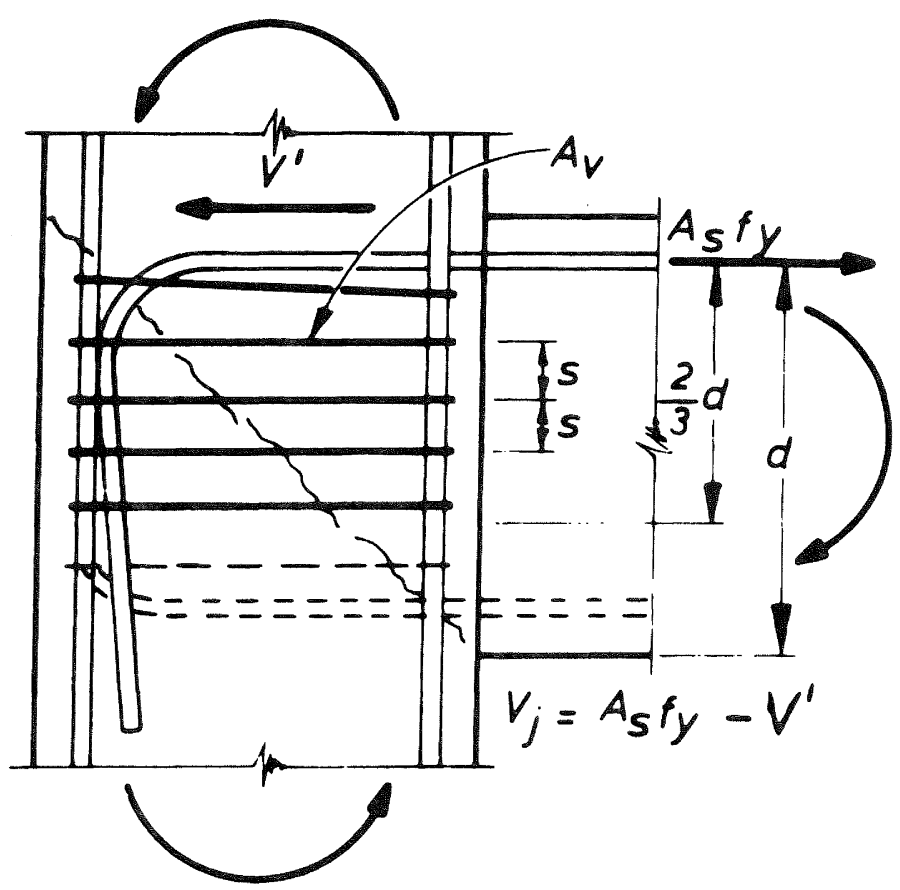

Fig. Il Effective ties resisting shear in an exterior beam-column joint. 


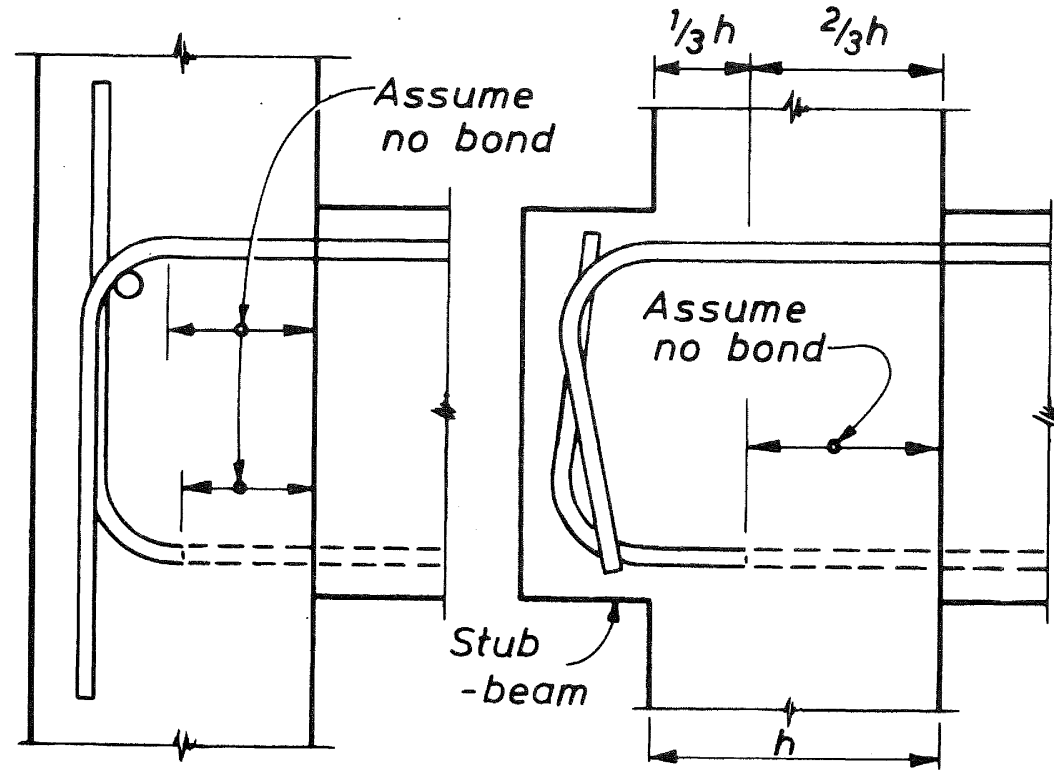

(a)

(b)

\section{Mechanical} anchorage

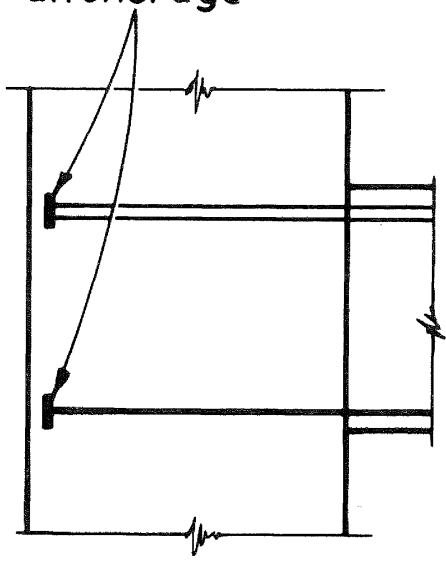

(c)

Fig. 12 Anchorage of beam bars in exterior column.

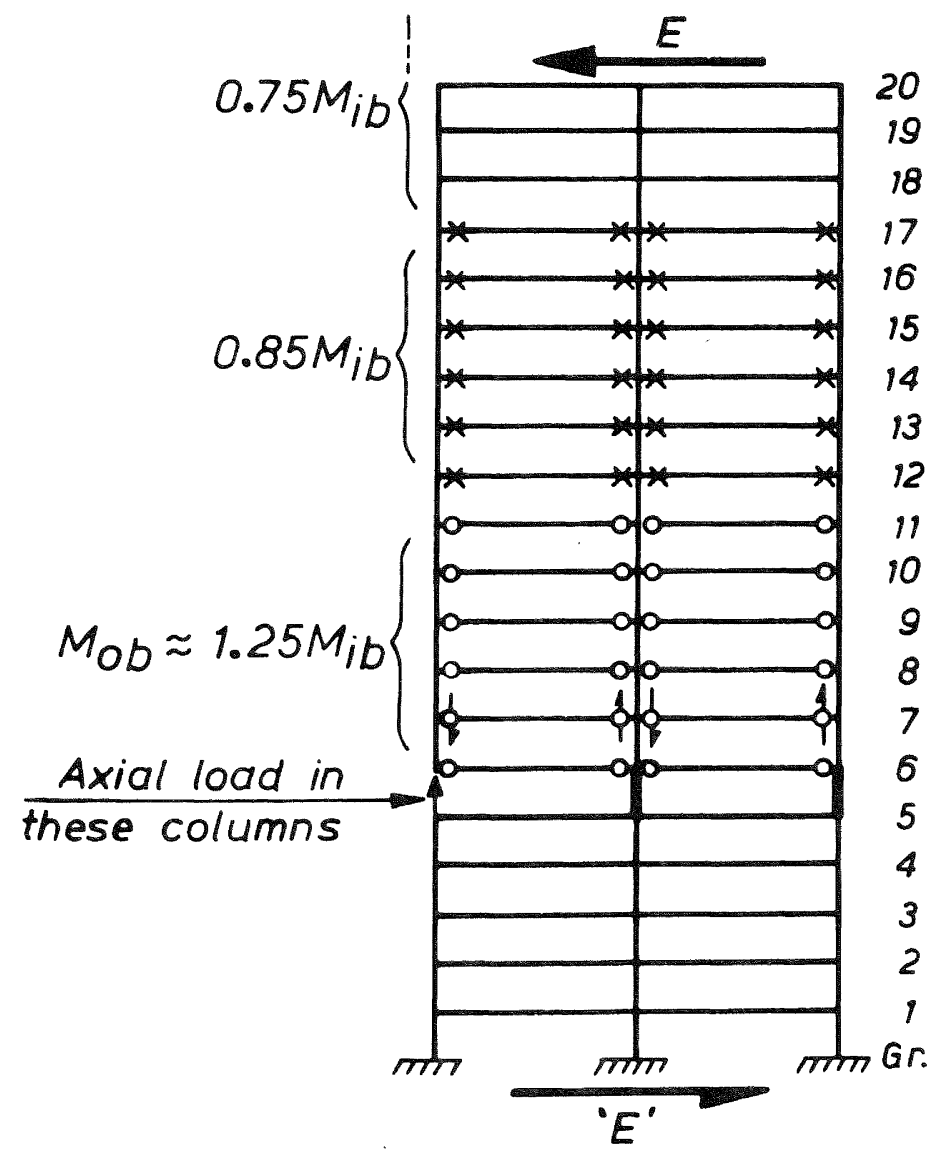

Fig. 13 Beam moment and plastic hinge pattern for evaluating earthquake induced axial loads in columns. 


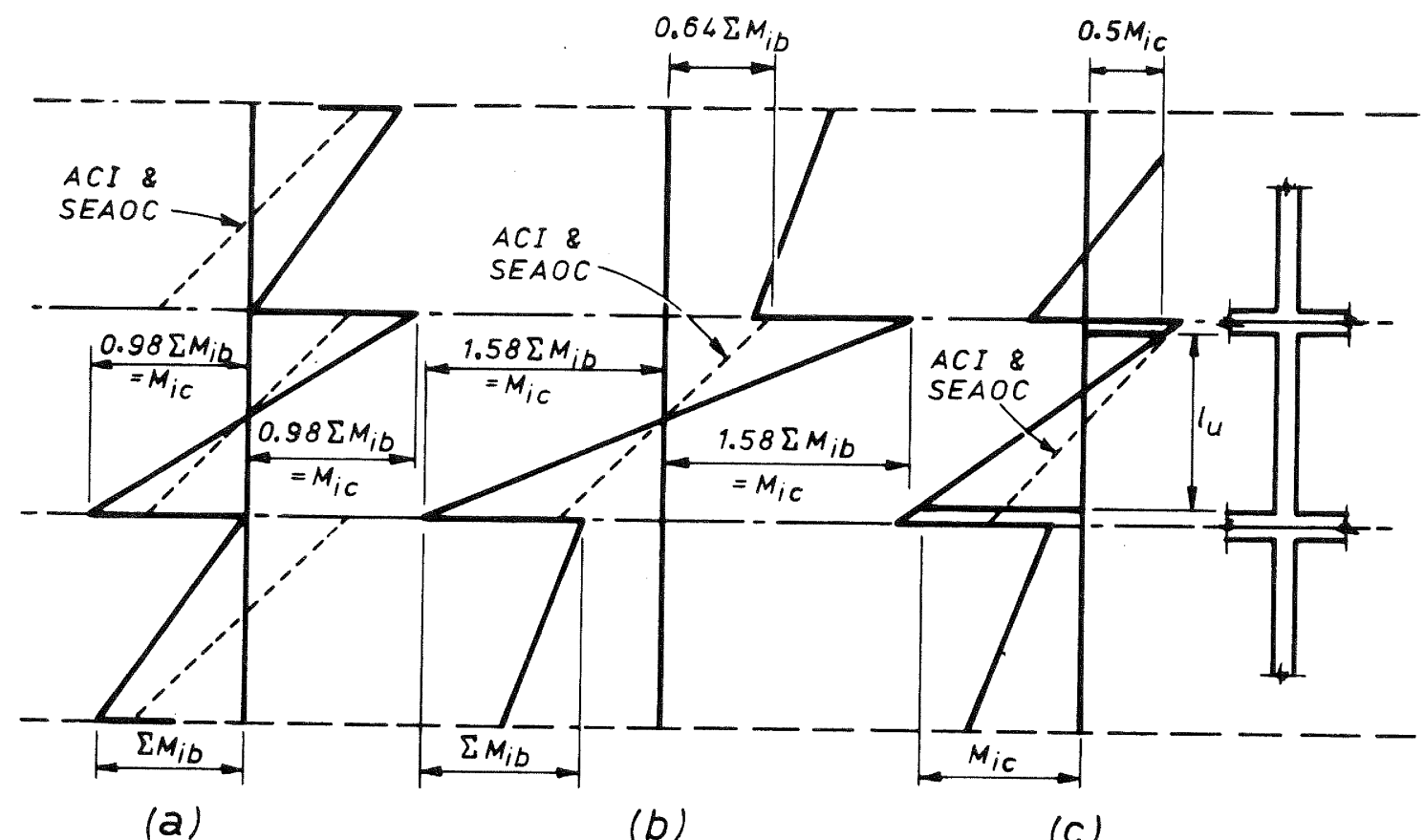

Fig. 14 Moment patterns to determine column shear forces. 